\title{
Receptive-Field Properties of Deafferentated Visual Cortical Neurons after Topographic Map Reorganization in Adult Cats
}

\author{
Yuzo M. Chino,, Earl L. Smith III, ${ }^{1}$ Jon H. Kaas, ${ }^{2}$ Yuji Sasaki, ${ }^{1}$ and Han Cheng \\ ${ }^{1}$ College of Optometry, University of Houston, Houston, Texas 77204-6052 and ${ }^{2}$ Department of Psychology, \\ Vanderbilt University, Nashville, Tennessee 37240
}

\begin{abstract}
When neurons in primary visual cortex of adult cats and monkeys are deprived of their normal sources of activation by matching lesions in the two retinas, they are capable of acquiring new receptive fields based on inputs from regions of intact retina around the lesions. Although these "reactivated" neurons respond to visual stimuli, quantitative studies of their response characteristics have not been attempted. Thus, it is not known whether these neurons have normal or abnormal features that could contribute to or disrupt an analysis of a visual scene. In this study, we used extracellular single-unit recording methods to investigate their stimulus selectivity and responsiveness. Specifically, we measured the sensitivity of individual neurons to stimulus orientation, direction of drift, spatial frequency, and contrast. Over $98 \%$ of all units in the denervated zone of cortex acquired new receptive fields after 3 months of recovery. Newly activated units exhibited strikingly normal orientation tuning, direction selectivity, and spatial frequency tuning when high-contrast $(<40 \%)$ stimuli were used. However, contrast thresholds of most neurons were abnormally elevated, and the maximum response amplitude under optimal stimulus conditions was significantly reduced. The results suggest that the striate cortical neurons reactivated during topographic reorganization are capable of sending functionally meaningful signals to more central structures provided that the visual scene contains relatively high contrast images.
\end{abstract}

[Key words: visual cortex, cat, retinal lesions, map reorganization, response properties, adult plasticity]

Traditionally, sensory systems in adult mammals have been considered to be highly stable in organization and virtually immutable. This view is now being modified because partial deafferentation of sensory representations in cortex are typically followed by topographic map reorganization with deprived neurons becoming responsive to the remaining inputs (see recent reviews by Kaas, 1991, 1994; Garraghty et al., 1994). Specifically, in the primary visual cortex of cats and monkeys, a small lesion of the retina of one eye, when matched by a visuotopically

\footnotetext{
Received Aug. 4, 1994; revised Sept. 27, 1994; accepted Sept. 30, 1994.

We thank Y. Blocker and $\mathrm{N}$. Jain for assistance with histology, S. Garcia and L. Kelly for assistance in data analysis, and $\mathrm{H}$. Bedell and D. Levi for comments on an earlier draft. This work was supported by NIH Research Grants EY-08128, EY-0361 I, EY-02686, and RR-07146.

Correspondence should be addressed to Yuzo M. Chino, College of Optometry, University of Houston, 4901 Calhoun Boulevard, Houston, TX 772046052 .

Copyright (C) 1995 Society for Neuroscience $0270-6474 / 95 / 152417-17 \$ 05.00 / 0$
}

overlapping lesion of the other eye, produces a zone of binocularly deprived cortex where neurons come to be responsive to portions of retina adjacent to the lesions (Kaas et al., 1990; Heinen and Skavenski, 1991; Gilbert and Wiesel, 1992). Similar phenomena have been reported to occur in auditory and somatosensory cortex after cochlear or peripheral nerve damage (see Kaas, 1991, 1994, for reviews).

Although rcactivation docs occur, it is not yct ccrtain how or if neurons in the reorganized cortex contribute to perception. For such neurons to play a useful role in sensory processing, it would seem necessary that they have normal or nearly normal receptive field characteristics. Presently, little is known about the response properties of individual, reactivated neurons because previous studies have concentrated on the conditions required for map reorganization. Another reason for investigating the response properties of individual neurons is that these properties should reflect the characteristics of the mechanisms responsible for reorganization. Normal properties would seem to require the reinstatement of very precise local connections. During development, such connections form as a part of activity-dependent selection processes (for reviews, see Movshon and Van Sluyters, 1981; Sherman and Spear, 1982; Mitchell and Timney, 1984; Friedlander and Tootle, 1990; Movshon and Kiorpes, 1990, 1993; Rauschecker, 1991; Garraghty and Sur, 1993) that may operate during the reorganization of mature sensory systems as well.

With the use of standard single-unit recording procedures and quantitative data-analysis methods (Chino et al., 1991, 1994), we asked whether or not the receptive fields of reactivated neurons are "normal." Specifically, we measured the responses of reactivated ncurons to drifting sinusoidal gratings as a function of orientation, the direction of drift, spatial frequency, and contrast. The results from reactivated neurons were compared to those obtained from units in normally innervated portions of the striate cortex and retinotopically matched neurons in normal cats. We found that stimulus selectivity of these originally deafferentated, but reactivated, neurons were surprisingly normal, although their overall responsiveness was dramatically reduced.

Some of the data have been presented briefly elsewhere (Sasaki et al., 1994).

\section{Materials and Methods \\ Subjects and retinal lesions}

An argon blue/green laser (HGM model PC) was used to make retinal lesions. Four normal adult pigmented cats, weighing between 2.5 and $4.0 \mathrm{~kg}$, were anesthetized with an intramuscular injection of ketamine hydrochloride $(30 \mathrm{mg} / \mathrm{kg}) / x y l a z i n e(4 \mathrm{mg} / \mathrm{kg})$ mixture and cycloplegia was produced with topically applied cyclopentolate hydrochloride (2 drops, $1 \%)$. An experimental lesion $(\sim 1 \mathrm{~mm}$ in diameter) was made in 
a

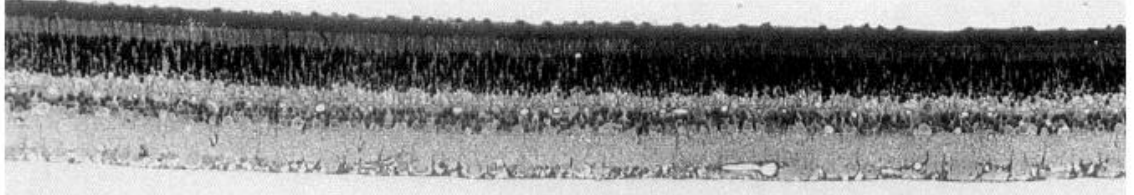

b
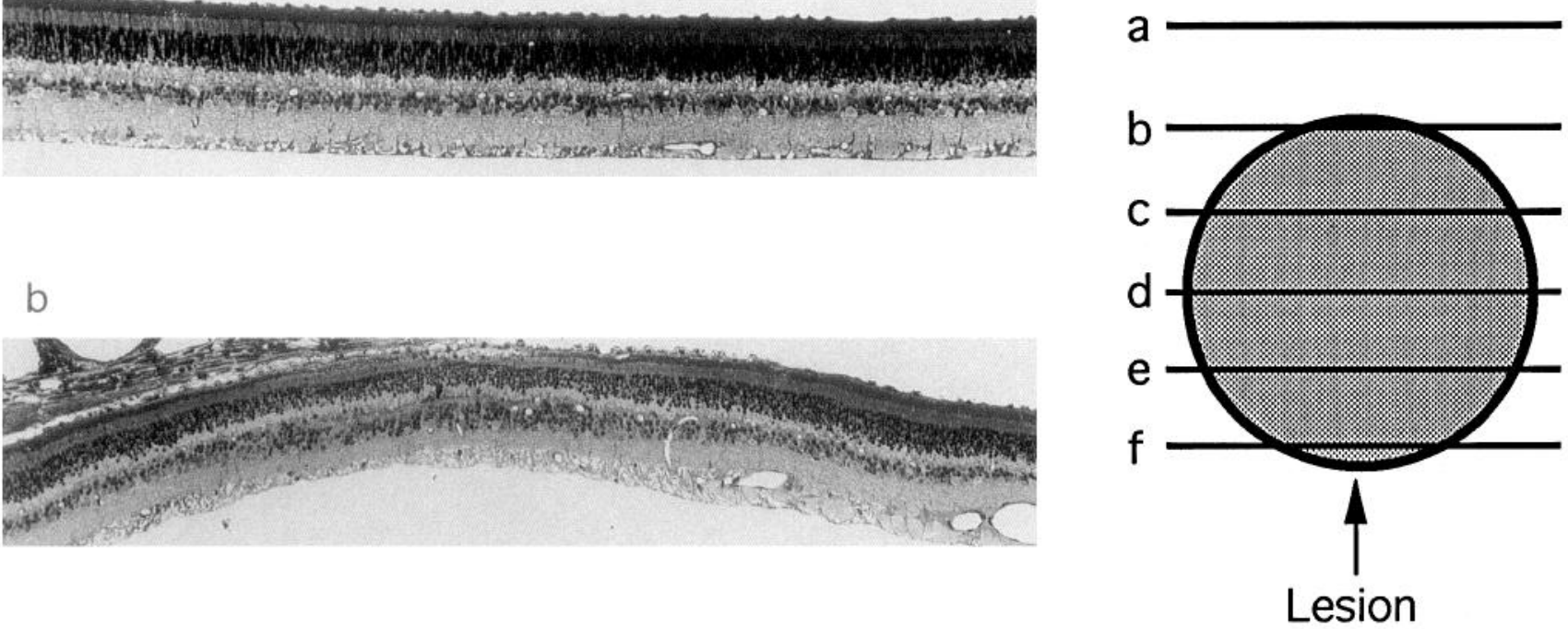

C

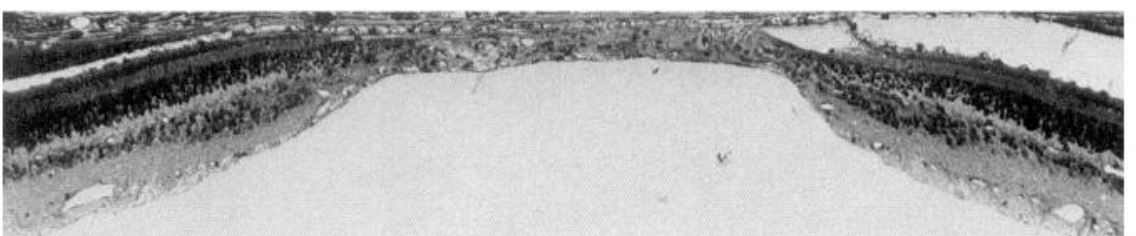

d

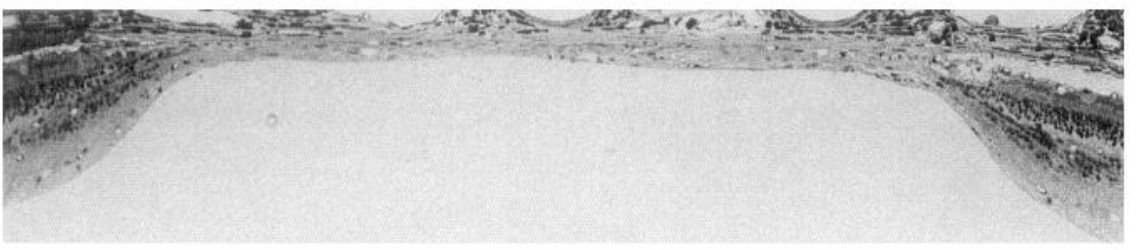

e

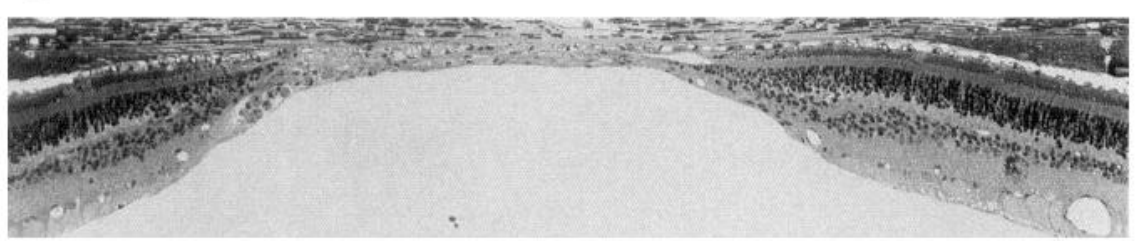

f

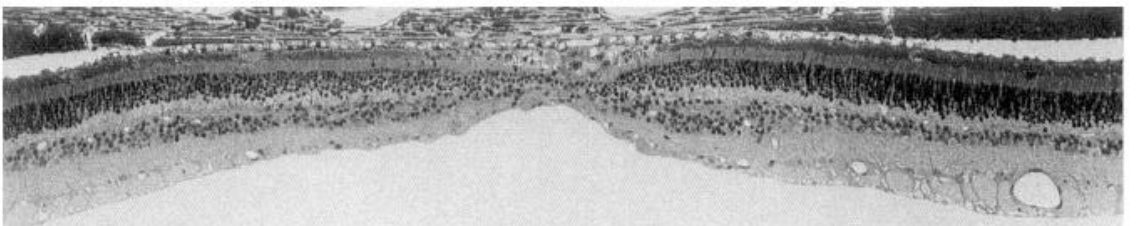


the upper nasal retina of the right eye between the optic disk and the area centralis. The laser parameters were set to make lesions that included the retinal ganglion cell layer (e.g., intensity $=0.3-0.8 \mathrm{~W}$, duration $=0.5 \mathrm{sec}$, and size $=1000 \mu \mathrm{m}$ in diameter). The left eye received a similar but much larger lesion in the corresponding area of the retina. Following laser surgery, the animals were housed under normally lighted visual conditions for 2.5-3 months prior to the time of recording experiments. Two normal cats without laser lesions served as control subjects.

\section{Animal preparation}

The cats were premedicated with atropine sulfate $(0.05 \mathrm{mg} / \mathrm{kg}, \mathrm{s.c}$.$) and$ initially anesthetized with an intraperitoneal injection of sodium pentobarbital $(40-50 \mathrm{mg} / \mathrm{kg})$. A femoral vein was cannulated with an indwelling catheter for the subsequent infusion of drugs. A tracheotomy was performed to facilitate artificial respiration, and the subjects were secured in a stereotaxic instrument. A rectal thermistor and electronically controlled heating pads were used to maintain core temperature at $38^{\circ} \mathrm{C}$. A craniotomy and durotomy $(10 \mathrm{~mm}$ in diameter) were made at H-C coordinate AP- 0 . A plastic cylinder was fitted over the hole and was fixed onto the skull with acrylic cement. After all surgical procedures were completed, the animals were paralyzed by an intravenous infusion of pancuronium bromide (a loading dose of $0.1 \mathrm{mg} / \mathrm{kg}$ followed by continuous infusion of $0.1-0.2 \mathrm{mg} / \mathrm{kg} / \mathrm{hr}$ ) in a $5 \%$ dextrose Ringer solution $(2.5 \mathrm{ml} / \mathrm{kg} / \mathrm{hr})$. The animal was artificially respired with a mixture of $59 \% \mathrm{~N}_{2} \mathrm{O}, 39 \% \mathrm{O}_{2}, 2 \% \mathrm{CO}_{2}$. The respiration volume was adjusted to maintain the end-tidal $\mathrm{CO}_{2}$ between $3.5 \%$ and $4 \%$. Anesthesia was maintained by the continuous intravenous infusion of sodium pentobarbital (Nembutal, $1-4 \mathrm{mg} / \mathrm{kg} / \mathrm{hr}$ in the $5 \%$ dextrose Ringer's solution). The anesthetic level was continuously monitored by observing the EEG, EKG, and heart rate, particularly in response to a periodic paw pad pinch.

The nictitating membranes were retracted by the topical application of phenylephrine hydrochloride (10\%), and cycloplegia and mydriasis were produced by $1 \%$ atropine sulfate topically instilled into the eyes. The animal's corneas were protected with rigid gas-permeable extendedwear contact lenses. Retinoscopy was used to refract the eyes for the $114 \mathrm{~cm}$ viewing distance used in all experiments. Additional lenses were used to correct refractive errors (spherical or cylindrical) of 0.50 diopters or greater. In addition, when a cell with a high-spatial-frequency cutoff was encountered, its responses were recorded as a function of spherical lens power to verify the proper refractive correction. The contact lenses were removed and cleaned periodically throughout the experiment. A fiber optic from a high-intensity light source was used to illuminate the retina and project the images of the optic disk, the area centralis, the experimental lesion, and the major blood vessels onto the tangent screen (Pettigrew et al., 1979). This procedure was frequently repeated to monitor eye drifts.

\section{Recording and stimulation}

An epoxy-insulated tungsten microelectrode was introduced into the brain through an electrically shielded guide tube. The plastic chamber was filled with $5 \%$ agar and sealed with melted wax. Action potentials were recorded and amplified by the use of conventional technology. A window discriminator provided standard pulses that were accumulated by a PDP-11/73 computer. A gimbaled mirror was used to project the receptive fields, which were mapped on the tangent screen, onto the center of a cathode ray tube (CRT) screen (P-31 phosphor). The CRT had a space-average luminance of $21 \mathrm{~cd} / \mathrm{m}^{2}$. Sinusoidal gratings were generated on the monitor with a microprocessor-based function generator that was controlled by the PDP-11/73 computer. The parameters of the drifting sinusoidal gratings (orientation, direction of drift, spatial frequency, temporal frequency, and contrast) could be controlled independently. A Pritchard Spectra Photometer equipped with an automated scanning slit was used to calibrate the luminance and contrast of the display. Stimulus contrast was defined as $\left(L_{\max }-L_{\min }\right) /\left(L_{\max }+L_{\min }\right)$, where $L_{\max }$ and $L_{\min }$ were the maximum and minimum luminance levels, respectively. The temporal frequency of all stimuli was kept at $3.12 \mathrm{~Hz}$.

\section{Data analysis}

The neurons' responses were accumulated in $10 \mathrm{msec}$ bins and compiled into peristimulus time histograms (PSTHs) that were equal in duration to, and synchronized with, the temporal cycle of the grating stimuli. The amplitude and phase of the temporal response components in the PSTHs were determined by Fourier analysis. To facilitate the comparisons of the relative effectiveness of different visual stimuli, the potential impact of variations in the responsiveness of the cortical neurons over time was minimized by collecting the quantitative data using a multihistogram technique (Movshon et al., 1978). In all experiments, the stimuli were presented multiple times in a randomly ordered sequence for relatively short periods (e.g., 10 cycles of a sine wave grating were drifted across the receptive field). During a given experiment, the newly randomized stimulus sequence was usually repeated three to six times, producing PSTHs for each stimulus that represented the neuron's response to 30-60 grating cycles. One or two blank stimuli (i.e., zero contrast controls) were included in each repeat of the newly randomized sequence to provide a measure of the neuron's maintained firing rate.

\section{Experimental procedures}

Mapping. Based on the previous data obtained from mapping experiments in our laboratories (Kaas et al., 1990; Chino et al., 1992), three to five penetration sites were selected on the postlateral gyrus between $\mathrm{H}-\mathrm{C}$ coordinates A-1 and P-2, and as close as possible to the midline. Single-unit activity was isolated in about $200 \mu \mathrm{m}$ intervals over the 6$7 \mathrm{~mm}$ distance of each penetration along the medial bank. For each well-isolated neuron, the minimum response field (Barlow et al., 1967) was first mapped on the tangent screen with hand held stimuli. In the experimental animals, all visual stimuli were monocularly presented to the eye with the small experimental lesion (contralateral to the recording hemisphere). To ensure the completeness of bilateral deafferentation, however, we tested whether a given unit could be activated by stimulation of the fellow ipsilateral eye. In normal control cats, the data were obtained under identical visual stimulation and recording conditions (i.e., by stimulating the contralateral eye alone while occluding the ipsilateral eye).

Determination of the border between the reorganized and normal cortical zones. During each penetration, it was determined whether cortical maps were reorganized in response to the retinal lesions and, if so, how reorganization was expressed. For the quantitative data analysis, we segregated the receptive fields of newly activated units from adjacent "normal" units based on the following procedures. We optically projected the experimental retinal lesion on the tangent screen, which appeared as a clear dark circle primarily due to damage to the tapetum. The visible borders of the lesions were distinct and matched well with the extent of the retinal damage (see Fig. 1d). Due to the sharpness of the retinal lesion, it was expected that the border of the cortical scotoma determined by our mapping experiments would closely correspond with the border of the projected retinal lesion. In each penetration, as our electrode advanced along the medial wall of the postlateral gyrus, the position of receptive fields systematically shifted laterally away from the vertical meridian into the periphery until the edge of the projected retinal lesion was encountered. With further electrode advancements, the normal lateral shift of receptive fields did not occur and no receptive fields could be mapped inside the area of the projected retinal lesion. Instead, because of topographic reorganization, the movement of our electrode into the deafferentated cortical zone was expected to cause newly acquired receptive fields to pile up at both the central and peripheral edges of the scotoma (i.e., no shift in position), to result in split receptive fields across the scotoma, and/or to cause an orderly receptive field progression around the scotoma (i.e., an obvious upward or downward displacement in receptive field position).

The cortical scotoma borders were most easily identified when the

Figure 1. Cross sections of the retina through the experimental lesion. The diagram on the right shows the approximate locations from which each cross section was taken. $a$, Normal region of retina. $b$ and $f$, Near the edge of the lesion. Note that damage is found primarily near the photoreceptors. $c-e$, Near the central region of the lesion. The damage extends across all retinal layers and the edges of the lesion are relatively sharp. Magnification, $100 \times$; scale bar, $100 \mu \mathrm{m}$. 

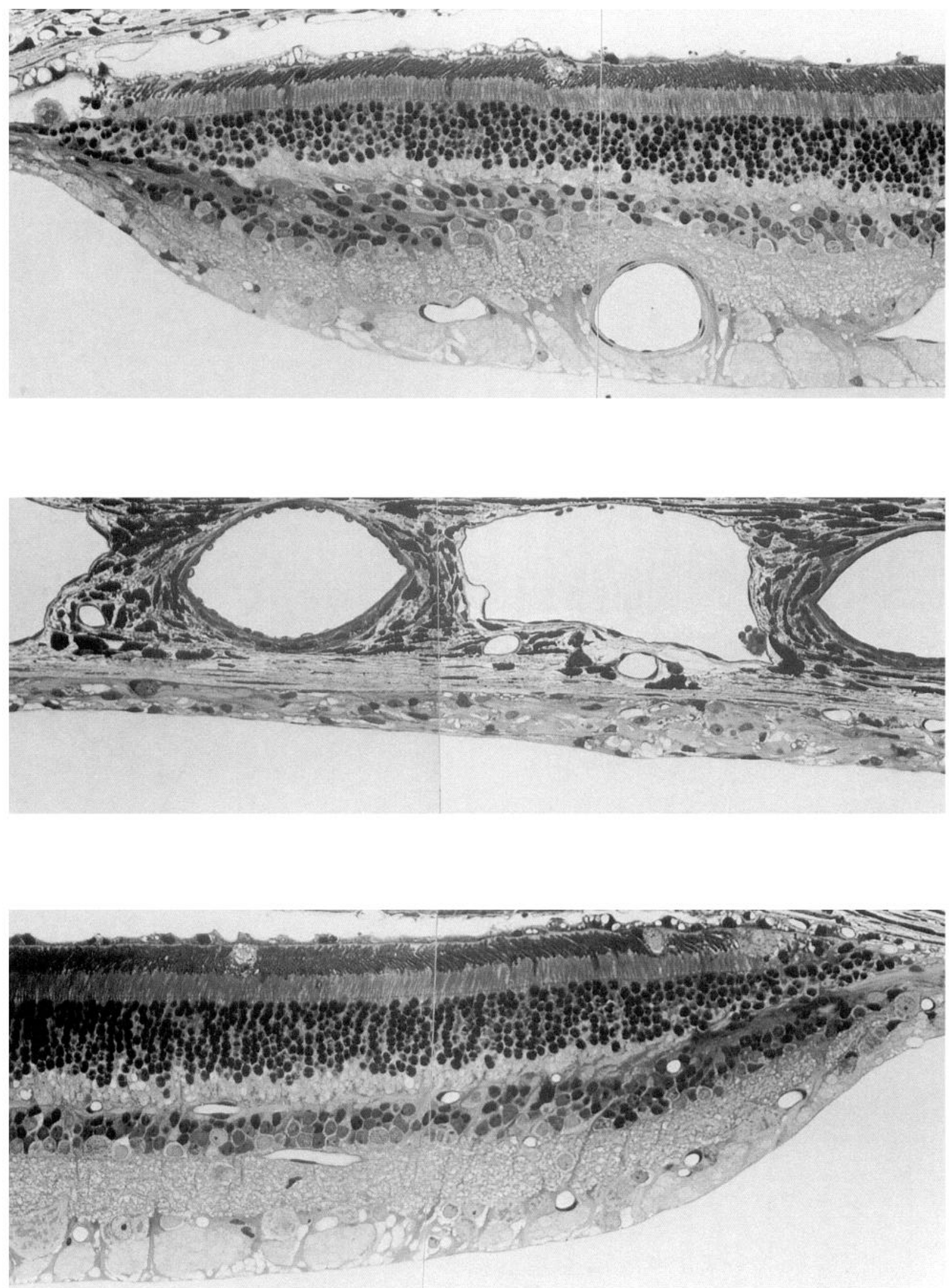
reorganized receptive fields were systematically displaced upward or downward, or when split receptive fields were obtained. In instances where the receptive fields simply piled up at the visible border of the lesion, the cortical scotoma border was identified by the observation that at least three consecutive receptive fields would have the same peripheral borders that corresponded to the border of the retinal lesion without systematic movement of the more medial receptive field borders. The more peripheral border of the cortical scotoma was identified as the first recording site at which there was a clear peripheral shift in receptive field position away from the border of the visible lesion. We felt that these criteria were reasonable because the borders identified using these criteria were frequently associated with either qualitative or quantitative changes in response properties.

Receptive field properties. Cells were classified as simple or complex on the basis of the temporal characteristics of their responses to a drifting sinusoidal grating of the optimal spatial frequency and orientation. Units were classified as simple cells if they exhibited a high degree of response modulation [(the amplitude of the first harmonic response/[the average response - the average spontaneous activity]) $>1$ ]; otherwise, the neurons were classified as complex cells (Skottun et al., 1991). For simple cells, the amplitude of the first harmonic component was used as the response measure for all subsequent analyses, and for complex cells, the amplitude of the DC component (i.e., the average firing rate) was used.

For selected units in the normal cortical areas and all units in the reorganized cortex, orientation bandwidth, direction selectivity, spatial frequency bandwidth, optimal spatial frequency and spatial resolution were quantitatively analyzed to assess each neuron's stimulus selectivity. In these measurements, stimulus contrast was held at $42 \%$, unless otherwise specified. The contrast threshold and the maximum response amplitude were also measured to quantify each unit's overall responsiveness.

Orientation tuning characteristics (i.e., optimal orientation and tuning bandwidth) were determined by measuring orientation response functions (stimulus orientation vs response amplitude). Responses were measured with a grating of the optimal spatial frequency presented at 12 different orientations. Both directions of stimulus movement orthogonal to the grating's orientation were assessed separately. The optimal orientation was determined as the stimulus orientation and the direction of drift that produced the highest response amplitude. The orientation bandwidth was measured at the response level equal to one-half the maximum response amplitude.

Direction selectivity was calculated from responses obtained at the cell's optimal spatial frequency and orientation by the following formula: direction selectivity index $=(P-N) / P$, where $P$ is the response amplitude for stimulus drift in the preferred direction and $N$ represents the response amplitude for stimulus drift in the opposite direction.

Spatial frequency response functions were measured using the optimal orientation and the preferred drift direction. The optimal spatial frequency was determined using a parameter file that contained 12 different spatial frequencies that ranged from 0 (i.e., whole field modulation) to 6.4 cycles/degree. The spatial frequency bandwidth was measured in octaves at the response level equal to one-half of the maximum response amplitude. The optimal spatial frequency for each cell was defined as the spatial frequency that produced the highest response amplitude. The spatial resolution (high-frequency cutoff) of each cell was defined as the spatial frequency at which the high-frequency limb of the spatial frequency response function intersected the mean noise level.

Contrast response functions were obtained at the cell's optimal orientation and spatial frequency and in the preferred drift direction. The contrast threshold was defined as the stimulus contrast at which a linear regression curve fitted over the linear response range of the contrast response function intersected the background firing rate.

\section{Histology}

At the end of recording experiments, electrolytic lesions (5-10 $\mu \mathrm{A}, 5-$ $10 \mathrm{sec}$, tip negative) were made at selected locations along the electrode penetrations to aid in the identification of recording sites. Animals were given an overdose of sodium pentobarbital $(80-100 \mathrm{mg} / \mathrm{kg}$, i.v.) and perfused through the heart initially with saline and then with a mixture

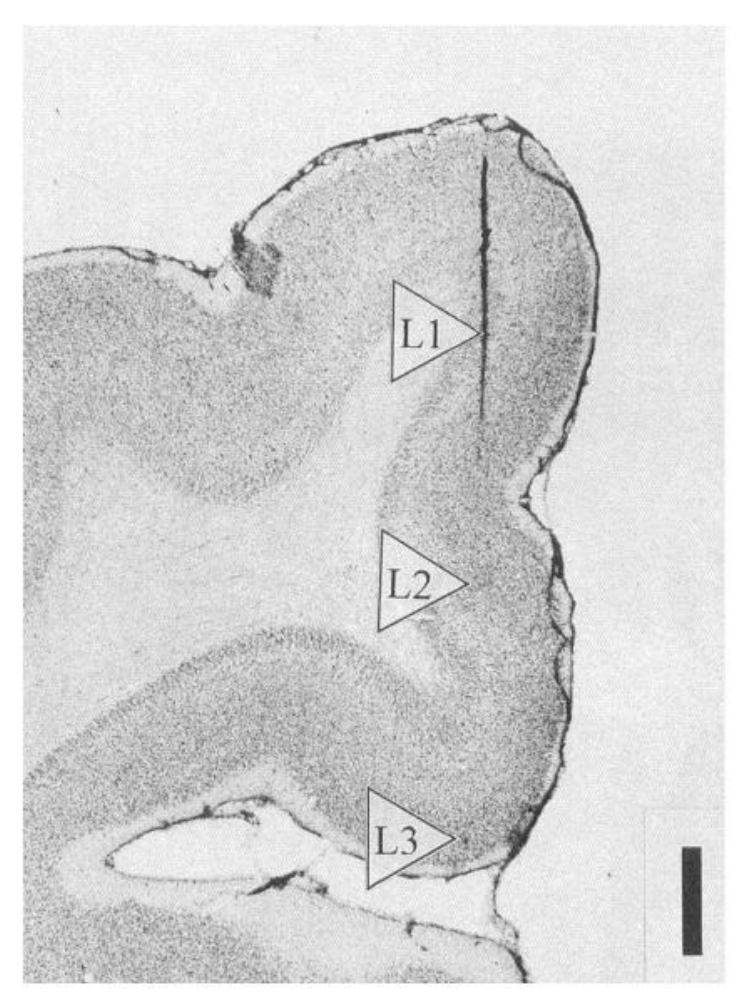

Figure 3. Typical recording sites. Frontal section through striate cortex of an experimental subject showing an electrode track. H-C coordinate of the penetration, P-2.5, L-0.7. The denervated zone of the cortex in this animal extended from slightly dorsal to lesion $1(L 1)$ to slightly ventral to lesion $2(L 2)$, thus covering a cortical distance of about $3 \mathrm{~mm}$. Scale bar, $1 \mathrm{~mm}$.

of $2 \%$ paraformaldehyde and $0.5 \%$ glutaraldyde in $0.1 \mathrm{M}$ phosphate buffer ( $\mathrm{pH} 7.4)$.

Retina. The eyes were enucleated and opened by an encircling cut, and the posterior eye cups were immersed in the fixative. After a few days, the eye cups were sectioned into a smaller piece that included the experimental lesion. The tissue was then dehydrated and infiltrated with Spurr's resin and hardened in molds. The embedded tissue was sectioned at $2 \mu \mathrm{m}$ outside the lesion and at every $1 \mu \mathrm{m}$ through the lesioned area. Sections were mounted and stained with toluidine blue to determine the extent of retinal cell damage.

Cortex and thalamus. The cortex and brainstem contralateral to the eye containing the smaller experimental retinal lesion were removed and kept overnight in fixative with $20 \%$ sucrose. The tissue was cut at $40 \mu \mathrm{m}$ on a freezing microtome in the frontal plane. Alternate sets of sections were stained with cresyl violet or processed for cytochrome oxidase (CO), GABA, and/or GAP43, using histochemical procedures (see Carroll and Wong-Riley, 1984, for CO) or immunohistochemistry for GABA (Chemicon Inc.) and GAP43 (Boehringer).

\section{Results}

\section{Retinal cell damage}

The nature and extent of retinal cell damage have been rarely documented in previous studies of map reorganization. In this study, we have extensively examined the retinas of experimental subjects with the use of standard histological methods. Representative photomicrographs of cross sections at five different locations within the experimental retinal lesion are illustrated 
Figure 4. A basic data set obtained from a normal control cat. $A$, Receptive field maps (top), preferred stimulus orientations (middle), and recording sites and depths from the surface in micrometers (bottom) are shown for two representative penetrations. $B$, Examples of orientation tuning (top row), spatial frequency tuning (middle row), and contrast response (bottom row) functions for three representative units encountered during penetration P4 $(A)$. Left, middle, and right columns show functions from units with receptive fields near the vertical meridian, at a $7^{\circ}$ eccentricity, and at a $13^{\circ}$ eccentricity, respectively. Open triangles on the right side indicate the level of spontaneous activity. $C$ (facing page), Summary graphs showing the changes in stimulus selectivity and responsiveness of units encountered during the two penetrations shown in $A$. Individual circles signify responses of individual units. The numbers for the recording sites correspond to those in $A$.
A
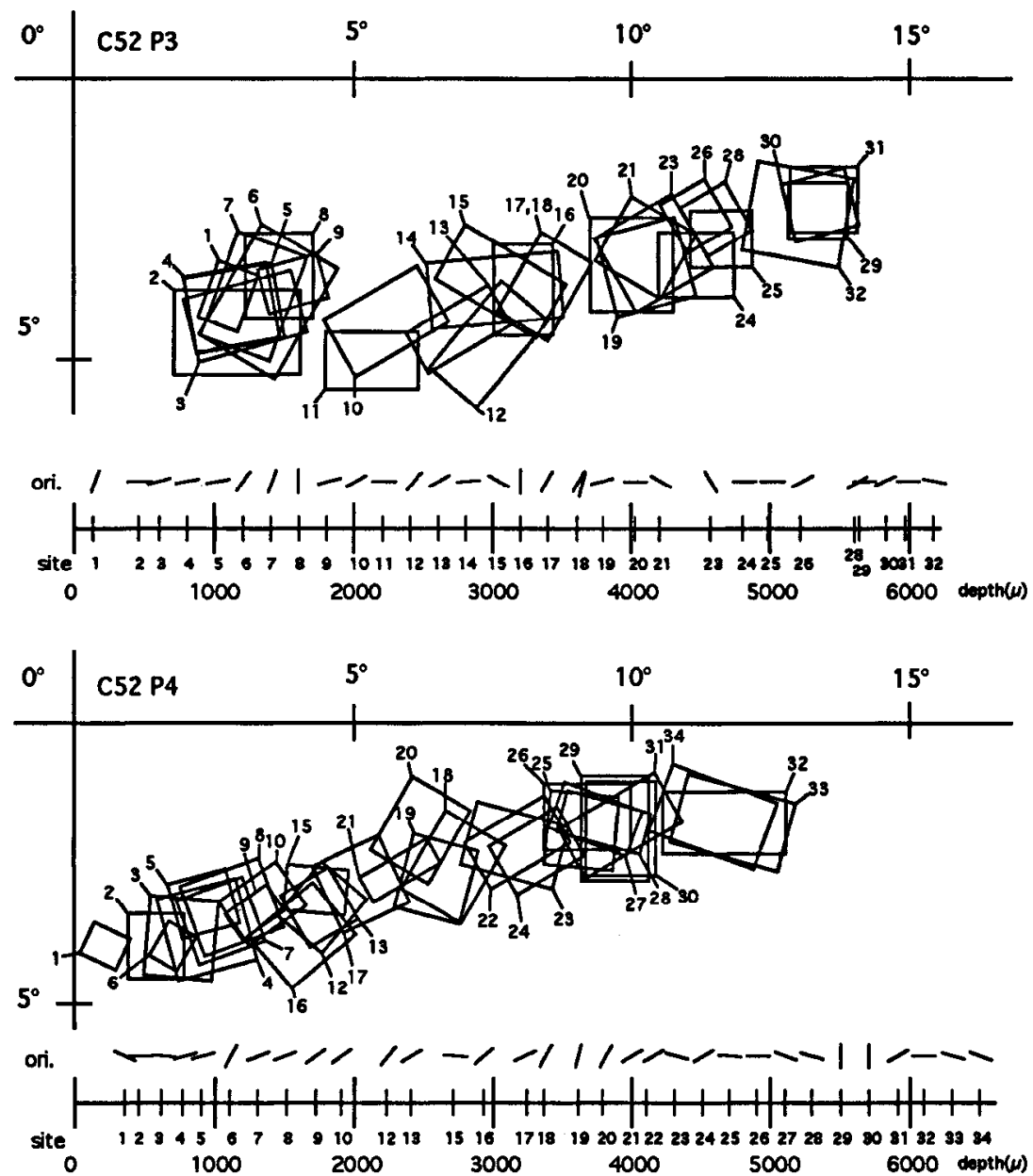

B
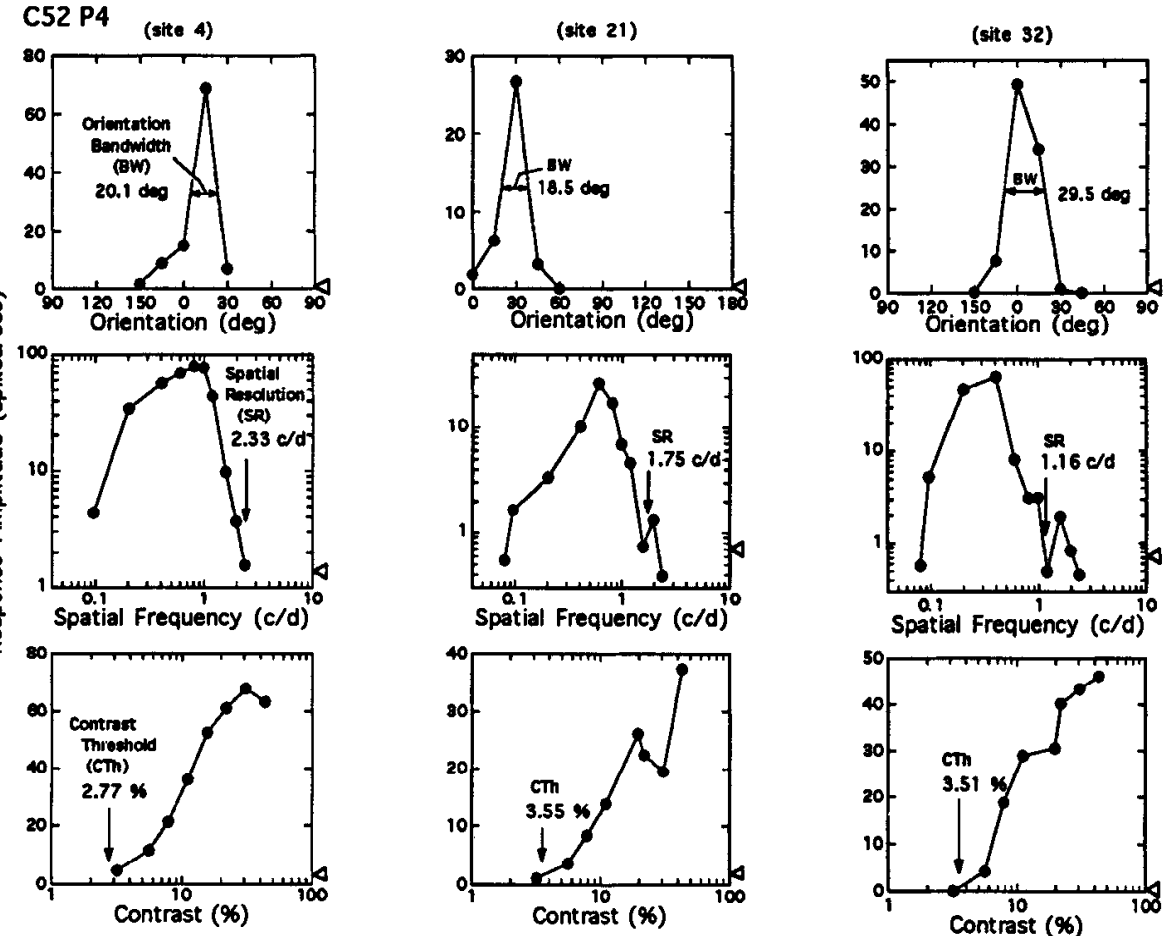
C
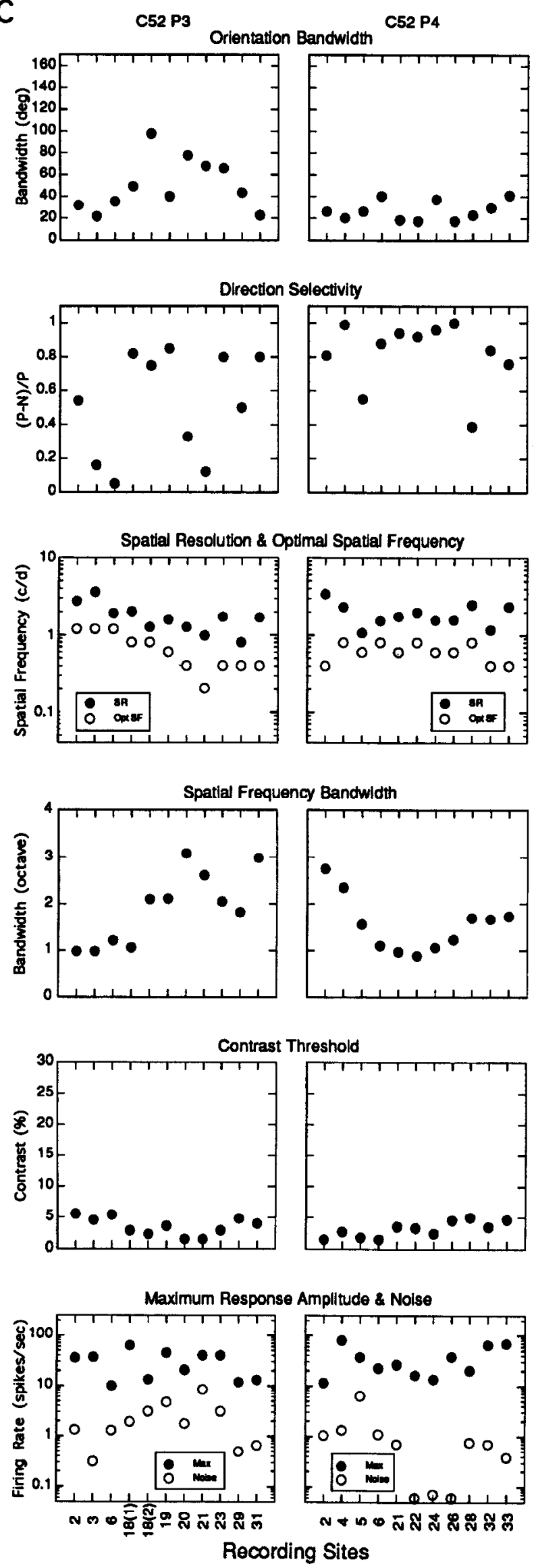

in Figure $1 b-f$. In addition, a photomicrograph of the normal retina adjacent to the lesion is also shown (Fig. 1a). Figure 2 illustrates photomicrographs of the cross section made at the center of the experimental lesion shown in Figure $1 d$ at a higher magnification. There are two findings that are critical to the cortical recording experiments. First, all retinal layers were damaged, including the ganglion cell layer (Figs. 1c,d;2). Thus, in contrast to retinal lesions that are restricted to photoreceptors (Gilbert and Wiesel, 1992), all afferent activity, not just visually evoked signals, was eliminated from the lesioned area. Second, the transition from the damaged area of the lesion to the "surrounding normal" zone was very sharp, extending a little over $100 \mu \mathrm{m}$. Moreover, the border of damage to the tapetum matched that of the retinal lesion, which made the lesion borders distinct and easily identified using fundus projection techniques. Consequently, the cortical scotoma determined during mapping experiments closely corresponded with the area of the retinal lesion optically projected on the tangent screen (Kaas et al., 1990; Chino et al., 1992; see also Figs. $5 A$ and $6 A$ of this study).

\section{Receptive fields in normal and lesioned subjects}

Recording sites. The photomicrograph in Figure 3 shows an example of an electrode penetration along the medial bank of the postlateral gyrus in an experimental cat. Arrowheads (L1-L3) indicate three sites along the track where small electrolytic lesions were made in this animal. The majority of our penetrations were made slightly more medial than this penetration; consequently, recording sites in the denervated zone (e.g., approximately between lesions 1 and 2 in this subject) were more frequently found in or near the supragranular layers of cortex.

Normal control subjects. Figure $4 A$ illustrates the receptive fields of units and their preferred stimulus orientations in a normal control cat. With the exception of the first $1-2 \mathrm{~mm}$ from the brain's surface, the receptive fields of units in both penetrations exhibited an orderly progression away from the vertical meridian into the periphery. Furthermore, the preferred stimulus orientation shifted regularly as the electrodes were advanced through the cortex.

In Figure $4 B$ examples of orientation tuning functions (top row), spatial frequency response functions (middle row), and contrast response functions (bottom row) from three representative normal control units (near the area centralis, midperiphery, and periphery) are illustrated. As anticipated, no remarkable differences were found between the units except that the optimal spatial frequency and spatial resolution of the unit closest to the area centralis (left column) were about one octave higher than those of the peripheral unit (right column).

Figure $4 C$ summarizes the response characteristics of all the units which were quantitatively analyzed during these two penetrations. The between-cell variability in orientation bandwidth (top row) and direction selectivity (second row) was substantial (range, $20-100^{\circ}$ and $0.0-1.0$, respectively), but there were no systematic changes as a function of retinal eccentricity. The only consistent changes as a function of retinal eccentricity were found in the neurons' optimal spatial frequency and high-frequency cutoffs (third row), which were generally lower at more peripheral locations. However, the spatial frequency bandwidths did not vary systematically as a function of retinal eccentricity (fourth row). The variability between units was smallest for contrast thresholds, which ranged between $1.6 \%$ and 6\% (fifth row) and were independent of retinal eccentricity. Finally, the maxi- 
Figure 5. A basic data set from an experimental animal. $A$, Receptive field maps (top), preferred stimulus orientations (middle), and recording sites and depths (bottom) for two representative penetrations. The large shaded circles indicate the extent of the cortical scotoma corresponding to the optically projected retinal lesion. Thick lines in the sequence of recording sites indicate the estimated area of the dencrvated zone of the cortex. The penetration marked $P 1$ corresponds to that shown in Figure 3. $B$, Examples of orientation tuning (top), spatial frequency tuning (middle), and contrast response (bottom) functions for representative units encountered during penetration $\mathrm{P} 1$ shown in $A$. The middle column shows responses from a reactivated unit in the reorganized zone, and the left and right columns demonstrate comparable tuning curves for units in normal zones central (left) and peripheral (right) to the reorganized zone. $C$, Summary graphs showing the changes in stimulus selectivity and responsiveness of units encountered during the two penetrations shown in $A$. The shaded areas indicate the reorganized zone of the cortex. The number for the recording sites correspond to those in $A$.

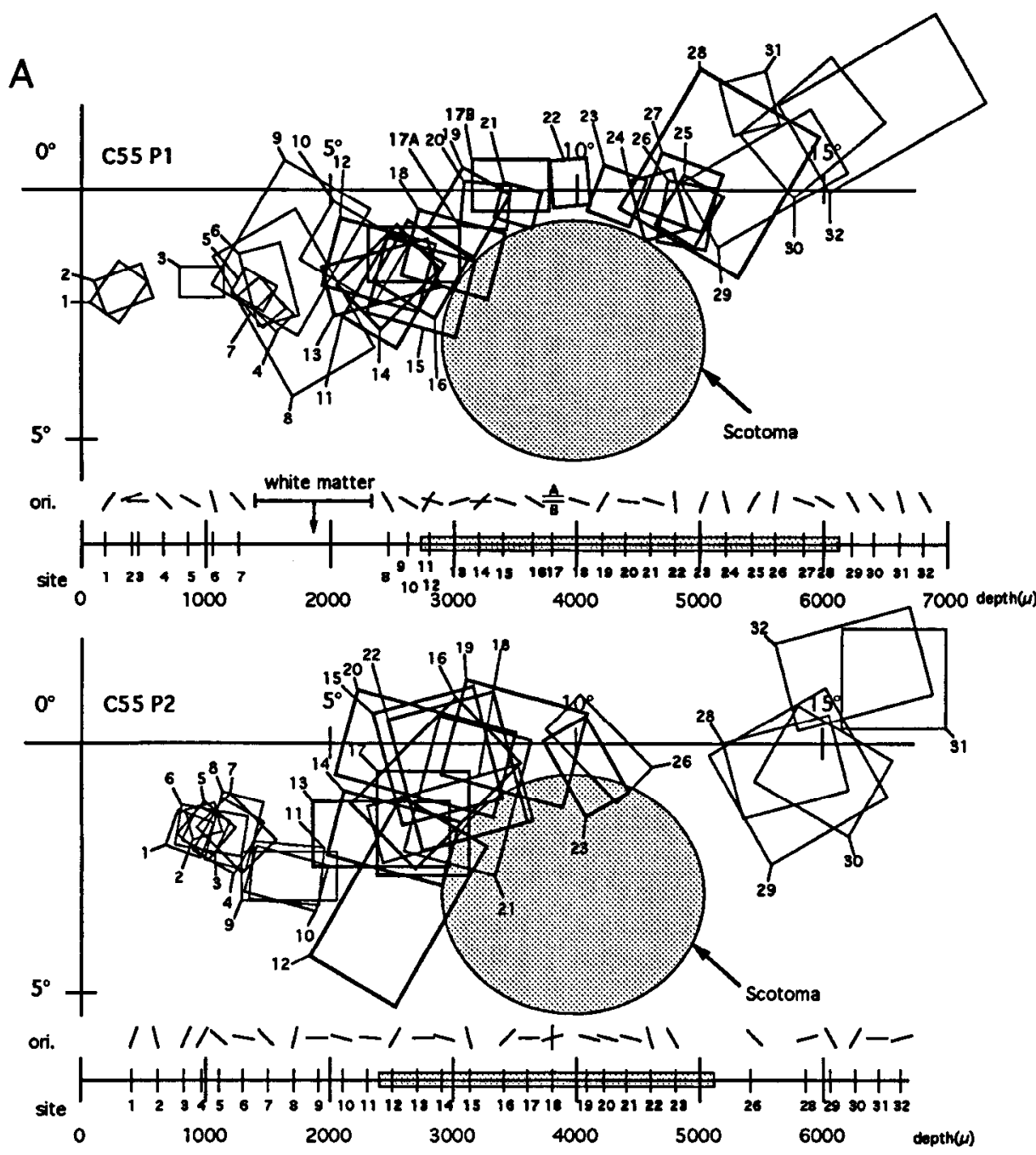

B

C55 P1 Normal Zone

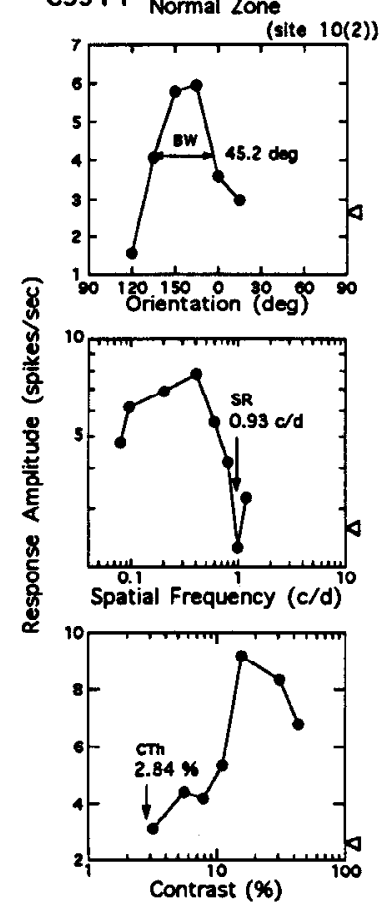

Reorganized Zone (site 13(2))

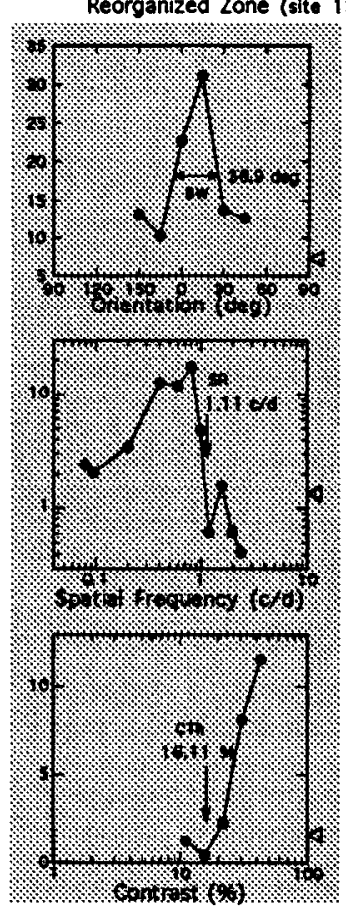

Normal Zone
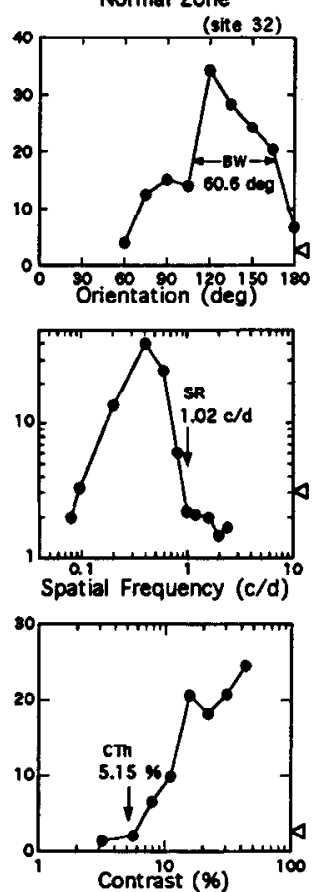
C
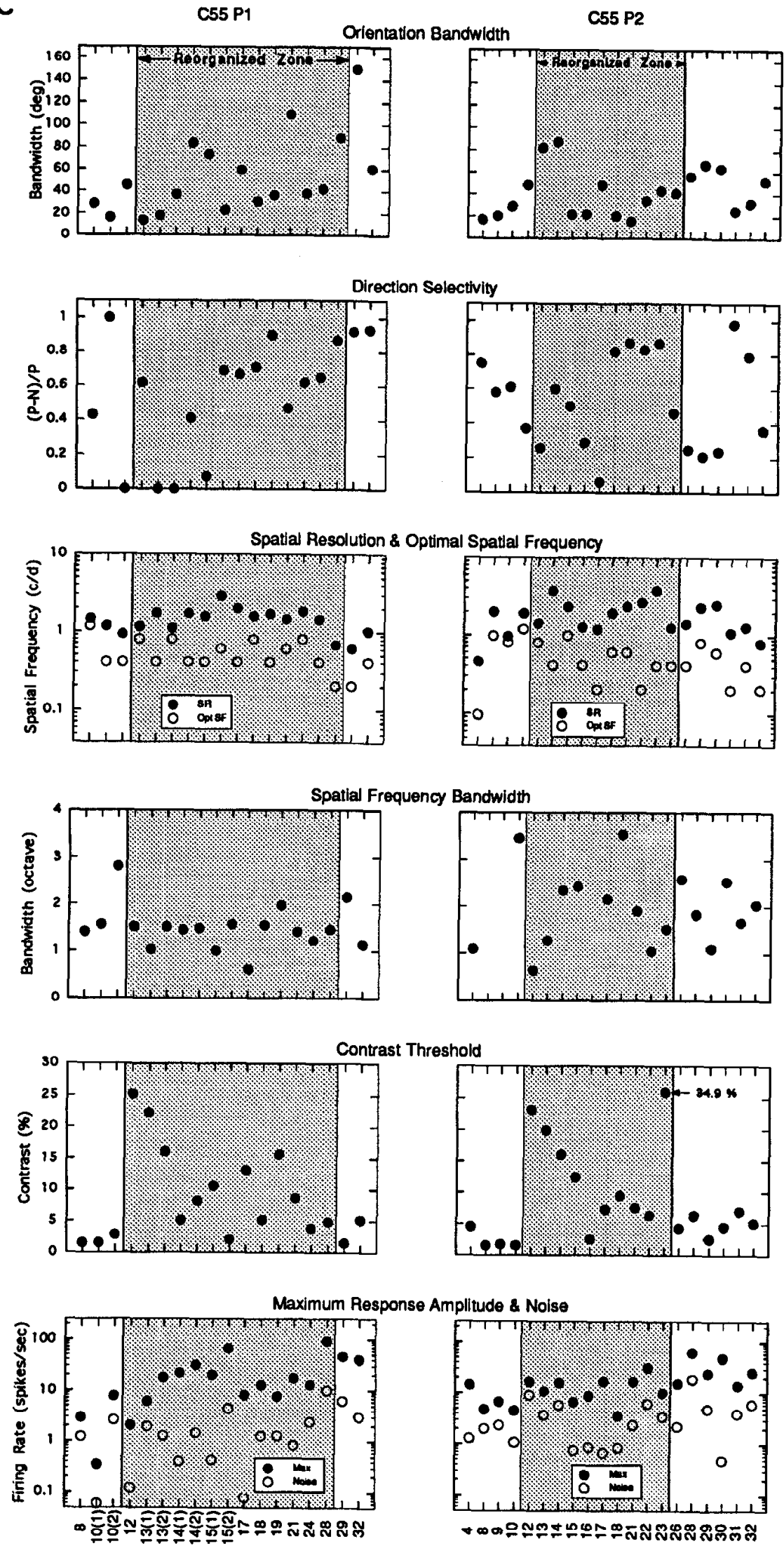

Rocording Sites

Figure 5. Continued. 
A
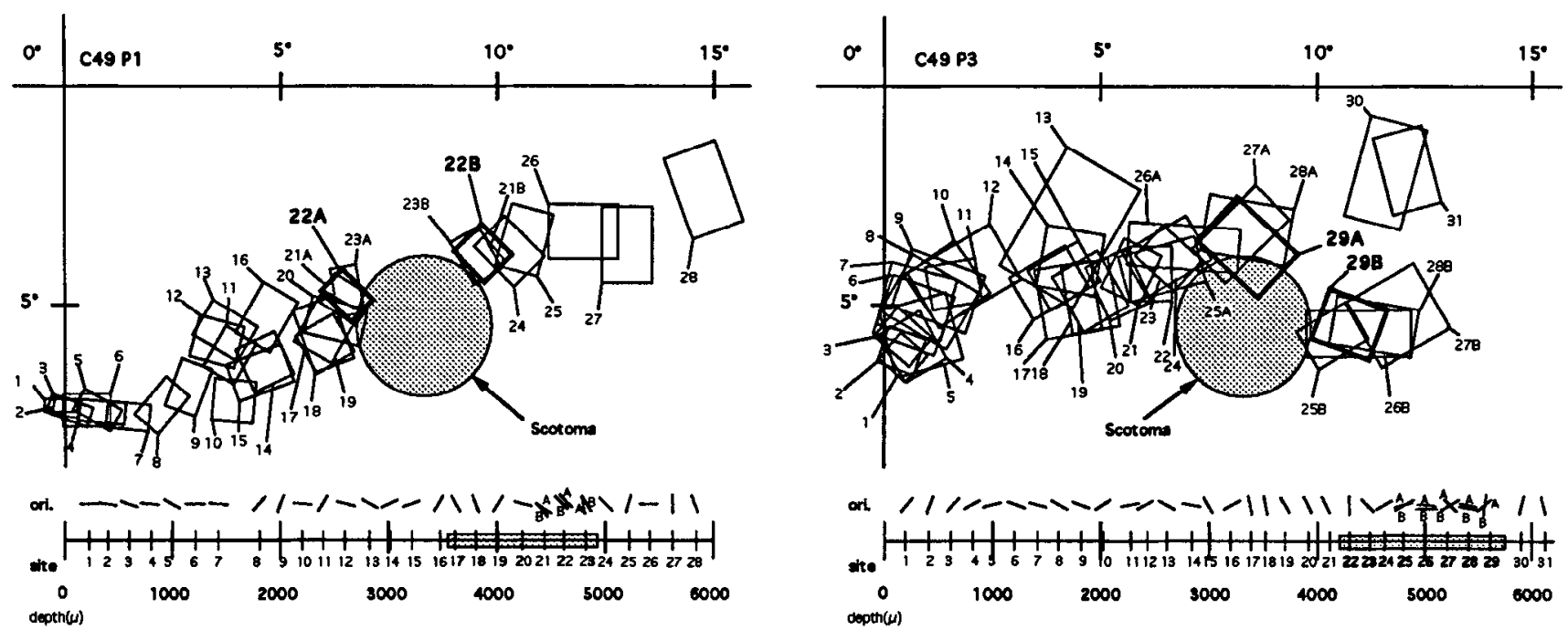

B
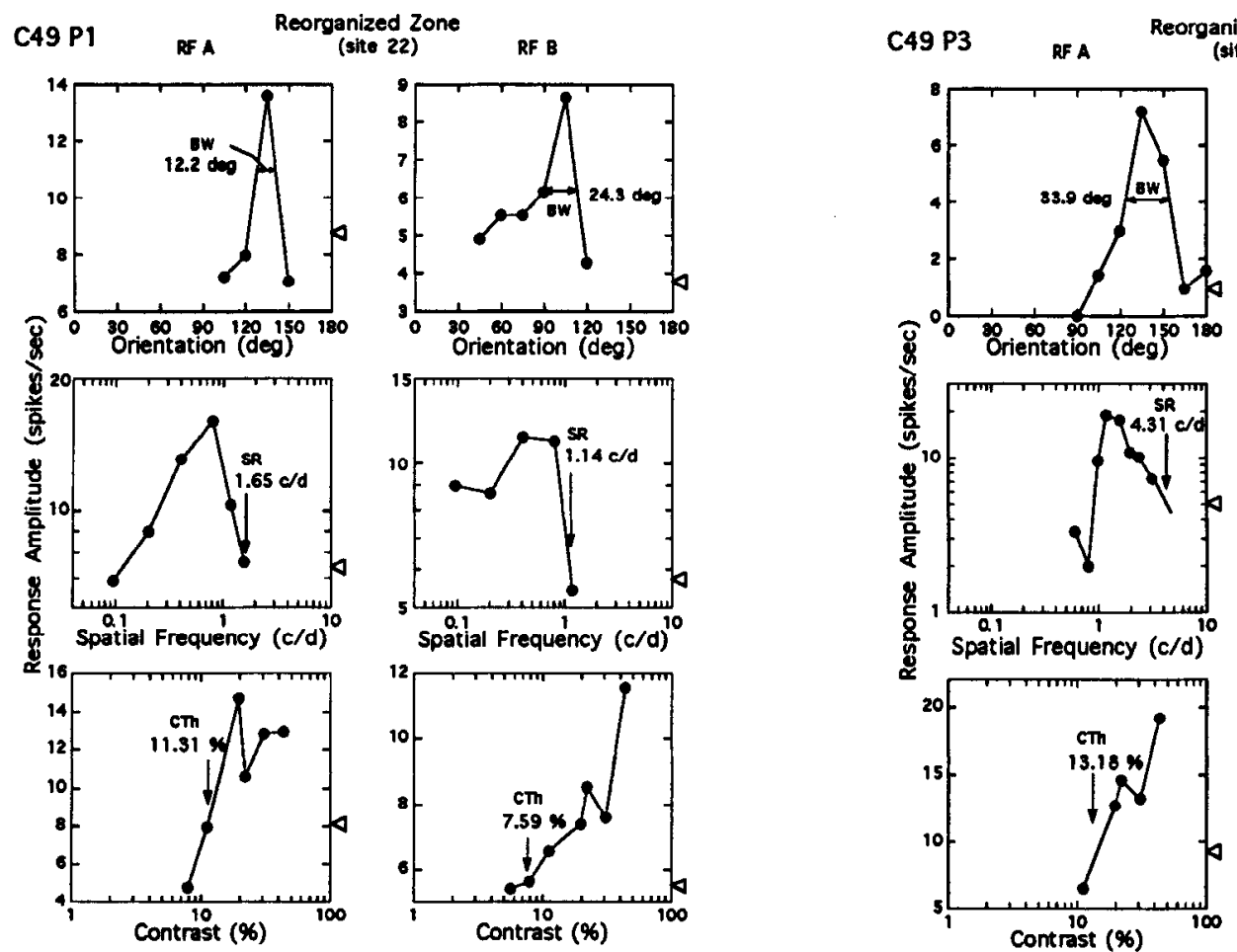

(site 29)

RF B
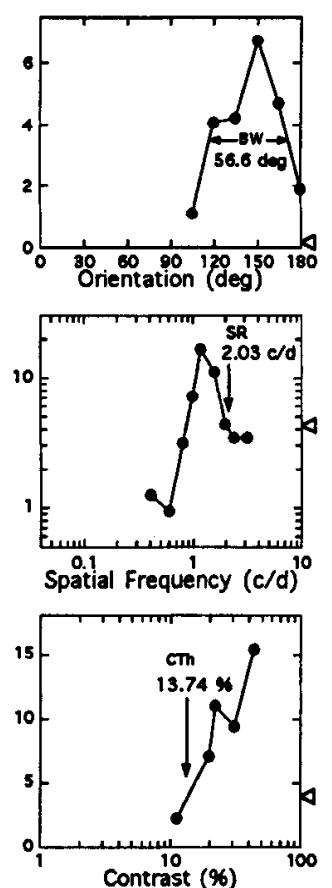

Figure 6. A data set from another experimental animal. Figures and conventions are the same as in Figure 5. In $B$, a pair of tuning functions are shown to illustrate the similarity between the two parts of the split receptive fields located on the opposite sides of the scotoma an individual reactivated unit $(A)$. Summary graphs in $C$ (facing page) illustrate the changes in stimulus selectivity and responsiveness for the cells encountered during the P3.

mum response amplitude and the amplitude of the maintained activity also showed random fluctuations in values between units (bottom row).

Deafferentated subjects. Figure 5 shows a similar data set including representative units from an experimental animal. The rcceptive field mapping (Fig. 5A) indicated that individual units in the denervated zone of the cortex (e.g., from site 11 to site 29 in P1 and from site 11 to site 23 in P2) had acquired new receptive fields around the edge of the retinal scotoma or blind spot. The nature of the map reorganization was very similar to the orderly receptive field progression around the scotoma reported in our previous studies (Kaas et al., 1991; Chino et al., 1992).

We compared the stimulus selectivity and responsiveness of reactivated neurons in the reorganized zone (reorganized units were identified on the basis of the criteria described in Materials and Methods) with those in the normal cortical areas of our experimental animals (normal zone) and with units in normal 

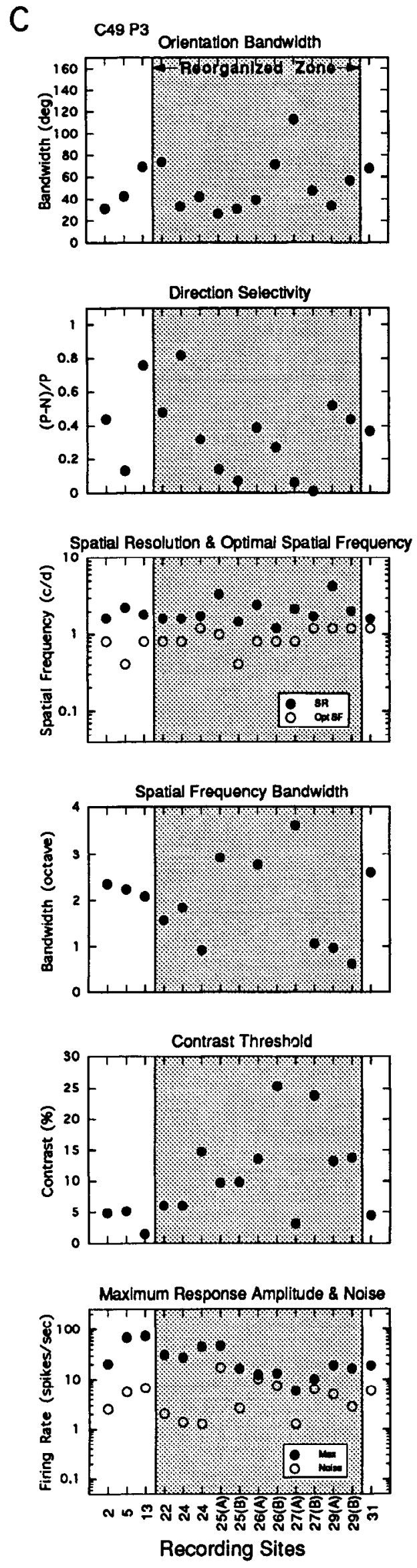

Figure 6. Continued. control cats. Figure $5 B$ illustrates examples of orientation tuning functions, spatial frequency response functions, and contrast response functions of units in the reorganized (center column) and normal zones (left and right columns) of cortex in an experimental cat. The orientation bandwidths of the reactivated neurons were very similar to those of units in normal areas or in normal control cats when high-contrast (42\%) stimuli were used (top row). Also the spatial frequency tuning characteristics of reactivated neurons did not differ substantially from those of normal zone units or normal control units (middle row). However, contrast sensitivity was drastically reduced in these reactivated units (bottom row). Specifically, the contrast thresholds were much higher $(16.1 \%)$ compared to normal zone units $(2.8 \%$ and $5.2 \%$ ) or to units from normal cats (e.g., Fig. $4 B$ ).

Figure $5 C$ shows the stimulus response characteristics of all the units encountered during the two penetrations shown in Figure $5 A$. The borders between the reorganized zone and the surrounding normal zones are marked with vertical lines. No systematic differences were found between control and reorganized ncurons in tcrms of their sensitivity to stimulus orientation (top row) or direction of drift (second row), and their spatial frequency tuning bandwidths (fourth row), high-spatial-frequency cutoffs, and optimal spatial frequencies (third row) were comparable. However, the contrast thresholds in the reorganized cortex (fifth row) were dramatically elevated compared with normal zone units or the baseline data from normal cats (Fig. $4 C$ ). The maximum response amplitude between reactivated units and normal zone units or units from normal cats (compare the bottom row with Fig. 4C) was not obviously different in these penetrations (but see the population data below). The level of maintained activity of reorganized neurons was also not different from normal.

An additional data set from a different experimental animal is illustrated in Figure 6 to demonstrate another, potentially important finding. This subject received a smaller retinal lesion ( $3.5^{\circ}$ in diameter). Consequently, the magnitude of map reorganization was smaller than that in the other subjects $(<2 \mathrm{~mm}$ in cortical distance). There were no silent areas in the cortex and an interesting pattern of cortical map reorganization emerged. Specifically, over a $1 \mathrm{~mm}$ cortical distance within the denervated zone, the majority of units showed two separate receptive fields on opposite sides of the scotoma (see sites 21-23 in P1 and 25-29 in P-3 in Fig. 6A). Among 12 units in four experimental subjects that exhibited split fields across the scotoma, the separation between the two fields ranged from $>3^{\circ}$ to $<10^{\circ}$ but in most cases was $\sim 5-6^{\circ}$. Interestingly, as illustrated in Figure $6 B$, the preferred orientations of the two fields were generally similar (within $30^{\circ}$ in 8 of 12 units). The summary diagrams in Figure $6 C$ provide additional evidence that the reactivated neurons in the reorganized zone had normal orientation tuning, direction selectivity, and spatial frequency tuning, while their contrast sensitivity was reduced.

\section{Receptive field sizes}

The receptive field dimensions of reactivated units (e.g., areas, widths, and lengths determined qualitatively with hand-held stimuli) were significantly larger than those of normal zone units or normal control units (Table 1). Previous studies also found receptive ficld expansion in multiunit recordings from rcorganized cortex (Kaas et al., 1990; Gilbert and Wiesel, 1992). However, the receptive field expansion for individual units was much more moderate than that observed in multiunit recordings, and 


\begin{tabular}{cllll}
\hline Table 1. & Receptive field sizes of reactivated neurons in reorganized cortical zone \\
& & $\begin{array}{l}\text { Reorganized } \\
\text { zone }(n=87)\end{array}$ & $\begin{array}{l}\text { Normal } \\
\text { zone }(n=105)\end{array}$ & $\begin{array}{l}\text { Control } \\
\text { cat }(n=108)\end{array}$ \\
\hline Area & Mean $( \pm \mathrm{SE})$ & $2.80 \pm 0.21^{*}$ & $2.19 \pm 0.17$ & $1.94 \pm 0.08$ \\
$\left(\right.$ degrec $\left.^{2}\right)$ & Median & 2.32 & 1.62 & 1.81 \\
& Range & $0.56-10.82$ & $0.39-9.33$ & $0.49-4.86$ \\
Width & Mean $( \pm \mathrm{SE})$ & $1.42 \pm 0.05^{*}$ & $1.29 \pm 0.06$ & $1.20 \pm 0.03$ \\
(degree) & Median & 1.31 & 1.11 & 1.16 \\
& Range & $0.75-3.27$ & $0.30-3.67$ & $0.50-2.36$ \\
Length & Mean ( $\pm \mathrm{SE})$ & $1.90 \pm 0.13 *$ & $1.57 \pm 0.06$ & $1.56 \pm 0.04$ \\
(degree) & Median & 1.76 & 1.51 & 1.51 \\
& Range & $0.65-11.33$ & $0.60-4.12$ & $0.75-2.81$ \\
\end{tabular}

* $p<0.01$ compared to normal zone or control.

the majority of experimental units with expanded receptive fields exhibited normal stimulus selectivity when tested with quantitative methods. Thus, receptive field expansion after peripheral deafferentation is not necessarily associated with reduced stimulus selectivity of individual neurons.

\section{Stimulus selectivity}

A population-based analysis was performed for the stimulus selectivity of the 56 reactivated units in the reorganized zones, 51 units in the normal zones of deafferentated subjects, and 48 neurons at corresponding sites in normal control cats. The distribution of orientation bandwidths for reactivated units (Fig. 7A, top) was very similar to those for normal zone units in the experimental animals (middle) and for normal control units (bottom) $\left(\chi^{2}\right.$ test, $\left.p>0.3\right)$. Direction selectivity of reactivated units (Fig. $7 B$ ) was also relatively normal except that the proportion of nondirectional units (e.g., DSI $<0.2$ ) was slightly higher among reactivated units $(25 \%)$ compared to the control groups
Figure 7. Normal selectivity of reactivated neurons to stimulus orientation and direction of drift. A, Orientation bandwidths of all units sampled in the reorganized (top) and normal zones (middle) of the experimental subjects and those in normal control cats (bottom). B, Comparable distributions of direction selectivity. None of the small differences between the three groups was statistically significant. Open triangles indicate the mean values for each group.

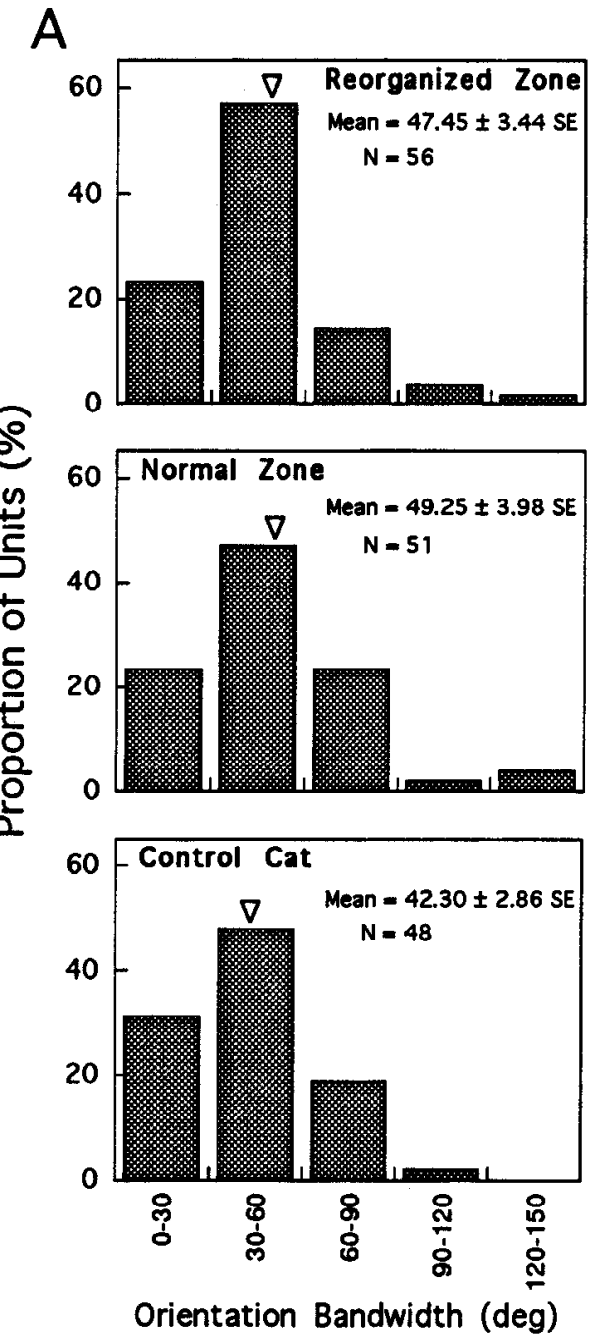


A

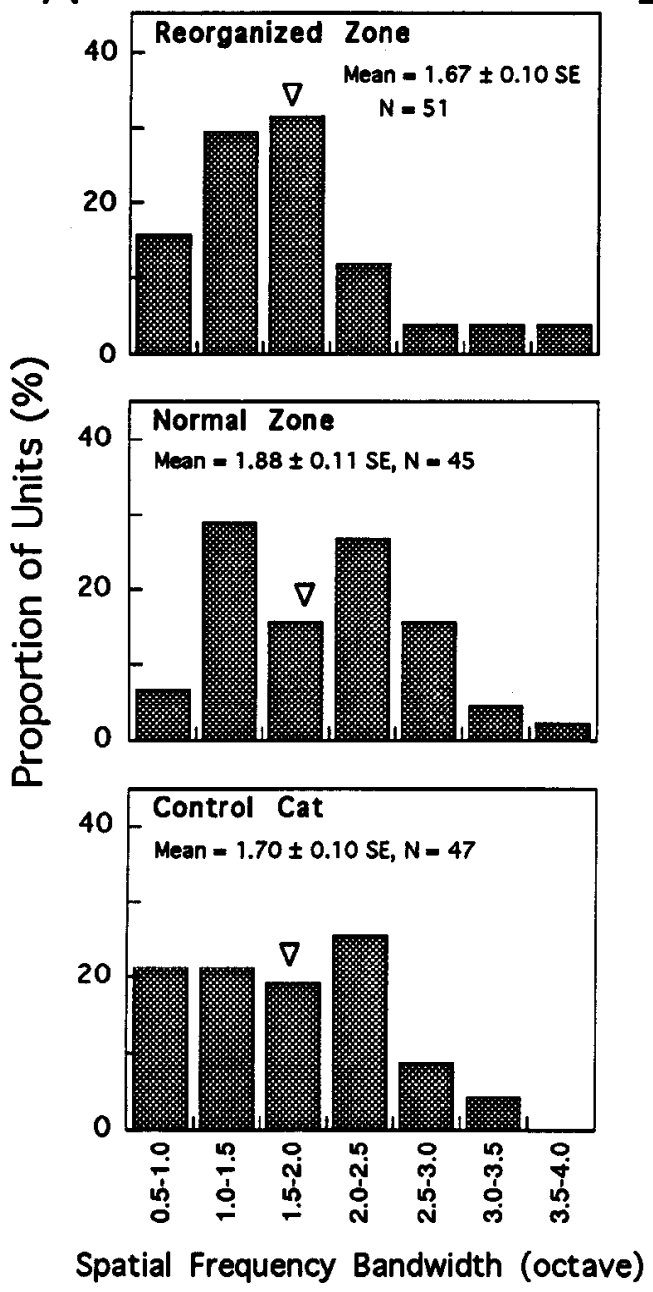

B
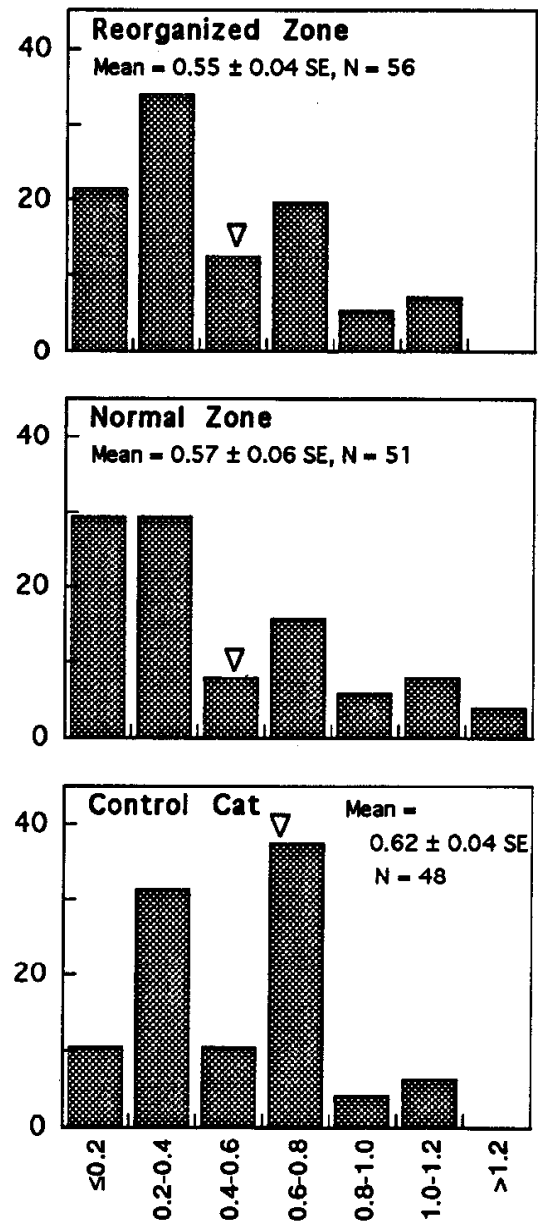

Optimal Spatial Frequency $(c / d)$
C
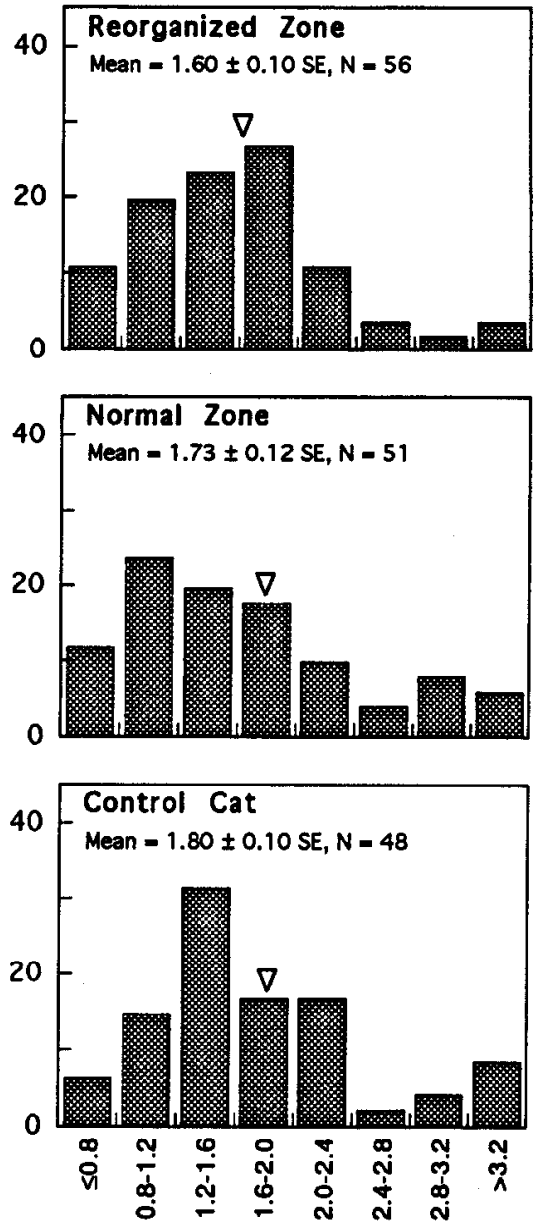

Spatial Resolution (c/d)

Figure 8. Normal sclcctivity of reactivated neurons to stimulus spatial frequency. $A$, Spatial frequency bandwidths. $B$, Optinlal spatial frequency. $C$, Spatial resolution. Conventions are the same as in Figure 7. No significant differences were found in either the distributions or mean values between the three groups.

$(12 \%)$. However, the distribution test $\left(\chi^{2}\right.$ test, $\left.p>0.2\right)$ or the mean direction selectivity index was not statistically different from units in the normal zone or normal control units ( $t$ test, $p$ $>0.1)$.

Figure 8 shows spatial frequency tuning characteristics of reactivated and control units. The spatial frequency response functions of reactivated neurons were as narrow as those in the rcorganized zones or in normal controls (Fig. 8A), which were very similar to the previously reported spatial frequency bandwidths in normal cat area 17 (Movshon et al., 1978; Chino et al., 1983). The small increase in the proportion of units exhibiting narrow bandwidths among reactivated neurons ( $\chi^{2}$ test, $p$ $>0.8$ ) may be due to a parallel increase in the proportion of units with a low maximum response amplitude (e.g., see Fig. $9 B$ ). With minor variations, the distributions for spatial frequency bandwidth (Fig. 8A), optimal spatial frequency (Fig. $8 B$ ), and spatial resolution (Fig. $8 C$ ) of reactivated units were very similar to those of either control cell group ( $\chi^{2}$ test, $\left.p>0.1\right)$. The small differences in mean optimal spatial frequency between the reorganized and normal zones or normal cats were not statistically significant ( $t$ tests, $p>0.1$ ). Similarly, the mean resolution of reactivated units was not significantly different from that for the normal zones or for units in normal cats ( $t$ test, $p>0.1$ ).

\section{Cell's responsiveness}

Although the stimulus selectivity of reactivated neurons was largely normal, their overall responsiveness under optimal stimulus conditions was clearly reduced. This deficit is reflected most dramatically in their reduced contrast sensitivity. Figure $9 A$ shows the distributions of contrast thresholds for reactivated and control units. Over $75 \%$ of reactivated units had contrast thresholds that were higher than $6 \%$ compared to only $10 \%$ of the units in the normal zones or normal control units. The mean differences between the units in the reorganized zone of cortex and the normal zone or normal control cats were highly significant ( $t$ test, $p<0.001$ ).

The mean maximum response amplitude of reactivated units (Fig. 9B, top row) was also lower than that of normal zone units (middle row) or normal control units (bottom row). This difference was primarily due to the skewed distribution for the maximum response amplitude of the reactivated units. For example, less than $30 \%$ of the reactivated units exhibited a maximum 
A

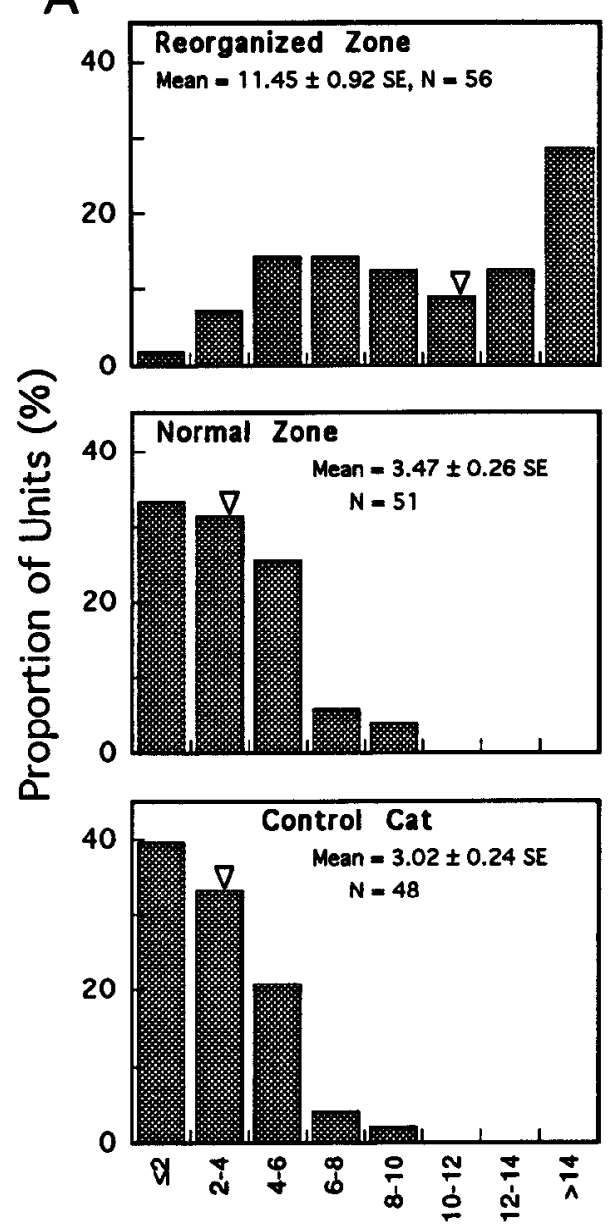

Contrast Threshold (\%)
B
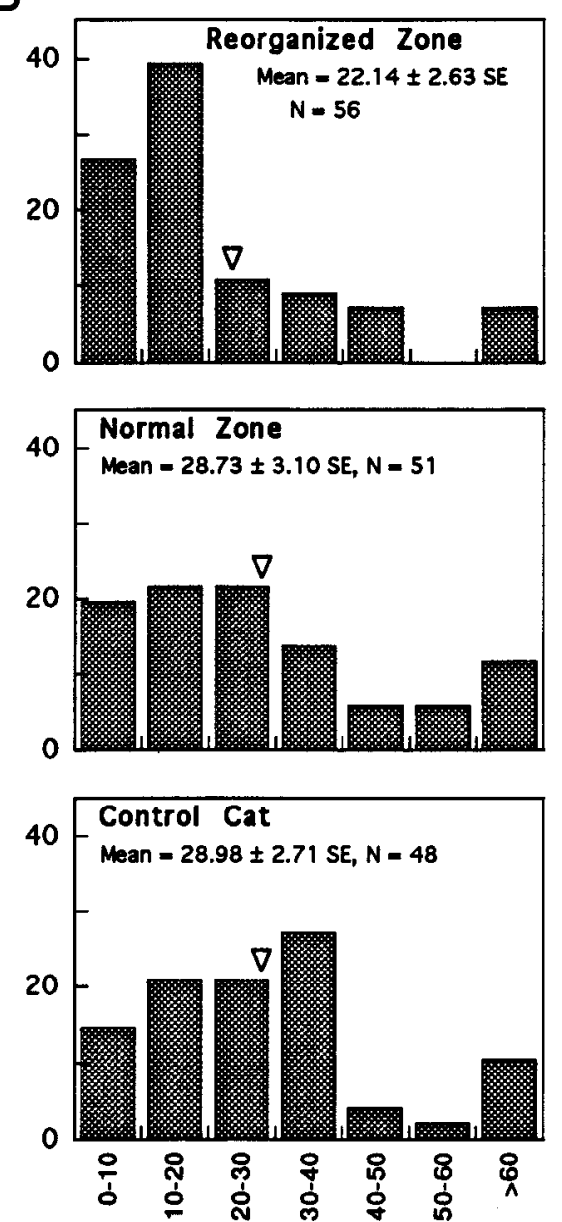

C
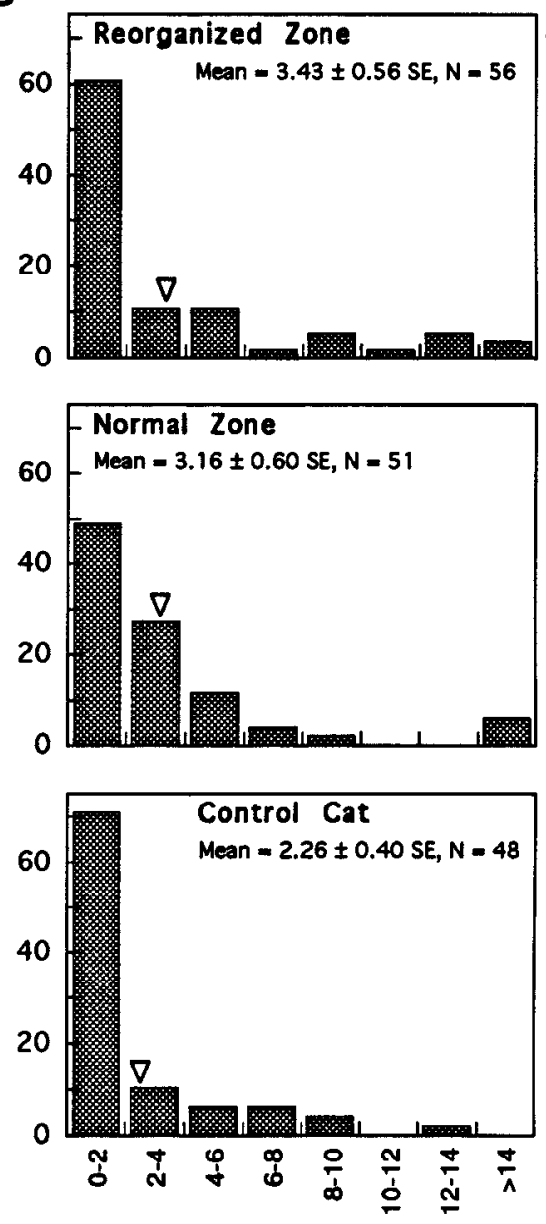

Maximum Response Amplitude (spikes/sec)

Figure 9. Reduced responsiveness of reactivaled nleurons. A, Contrast thresholds of cells in the reorganized (top) and normal zones (middle) of the experimental animals, and those from control cats (bottom). There was a dramatic elevation of contrast thresholds in a large proportion of reactivated units. $B$, Maximum response amplitude under optimal stimulus conditions for individual units. More reactivated units exhibited firing rates lower than $20 \mathrm{spikes} / \mathrm{sec}$. $C$, Spontaneous activity of individual units. Little differences were found among the three groups.

response amplitude greater than 20 spikes/sec, whereas over $60 \%$ of normal zone units and normal control units responded with peak firing rates greater than $20 \mathrm{spikes} / \mathrm{sec}$. The differences in the reactivated and control distributions were significant $\left(\chi^{2}\right.$ tests, $p<0.005$ ). Note that the distribution of maintained firing rate for the reactivated neurons (Fig. $9 \mathrm{C}$ ) was virtually the same as those for the two control groups ( $\chi^{2}$ test, $p>0.1$ ), which suggests that on average the "signal-to-noise ratio" is reduced in the reactivated neurons.

\section{Simple versus complex cells}

Although the sample sizes were relatively small, complex cells were more frequently encountered in the reorganized zones (41 of 55) of the lesioned animals than in the normal zones of our experimental subjects ( 29 of 51 ) or in the normal control cats (28 of 48). However, none of the present findings for either stimulus selectivity or responsiveness of reactivated units was systematically related to whether the cells had simple or complex receptive fields.

\section{Histology of the reorganized cortex and deprived thalamus}

The reactivated zone of cortex in two of the experimental subjects (C55 and C56) was examined for possible alterations in the expression of cytochrome oxidase ( $\mathrm{CO}$ ), the inhibitory neurotransmitter GABA, and the growth-associated phosphoprotein $\mathrm{G} \wedge \mathrm{P} 43$. We found no obvious differences between reactivated and control zones for any of these measures. Although our sample number is small, these results suggest that at the time of complete reorganization, the levels of metabolic activity, inhibition based on GABA, and neuronal growth were roughly comparable in reactivated and adjoining regions of the visual cortex.

We also examined the deactivated zone of the lateral geniculate nucleus (LGN) in these two cats. While there was no obvious increase or decrease in GABA expression, both cats demonstrated an increase in GAP43 in the deprived zone, especially in the neuropile of the A, A1, and C1 layers. This result suggests that the deprivation due to the loss of retinal ganglion cell arbors in the LGN results in the growth and structural reorganization of remaining elements, but it is known from previous studies that little retinotopic reorganization occurs at the level of the LGN (e.g., Eysel et al., 1981; Eysel, 1982; Gilbert and Wiesel, 1992).

\section{Discussion}

The major finding of this study is that the receptive fields of reactivated neurons in the topographically reorganized adult vi- 
sual cortex are surprisingly normal except for their reduced contrast sensitivity and responsiveness.

\section{Determination of the reorganized zone}

Before discussing the significance of the present findings, we should address two issues critical to this study: (1) whether the map reorganization is truly a cortical phenomenon instead of a reflection of alterations in the retina or LGN, and (2) how we determined which deafferentated neurons were reactivated during recovery (i.e., which units were in the reorganized zone).

With respect to the first issue, it is possible that this type of cortical map reorganization could simply reflect precortical phenomenon. Stimulation of large retinal areas outside the classic receptive field of ganglion cells is known to initiate strong excitatory responses in some retinal neurons, for example, the "shift" or "McIlwain effect" (McIlwain, 1966; Barlow et al., 1977). This retinal phenomenon is presumably mediated by the horizontal processes of amacrine cells in the inner plexiform layer (Barlow et al., 1977). Thus, retinal phenomenon could mimic topographic cortical reorganization if the retinal lesion included the photoreceptors but not inner retinal neurons, especially if the fellow eye was not deafferentated. It is possible that the presumed "cortical reorganization" observed in some recent studies (e.g., Schmid et al., 1993, 1994) immediately after retinal lesions which were limited to the photoreceptors was in fact a reflection of normal retinal mechanisms.

We are confident that retinal effects did not influence our results because our lesions (and those in our previous studies) involved all retinal layers including the ganglion cell layer (Figs. $1,2)$. In this respect, the cortical map reorganization in our studies could not be observed until we deafferentated the fellow eye (Chino et al., 1992). Furthermore, long recovery periods after deafferentation typically resulted in more complete (and larger) reorganization (Kaas et al., 1990; Chino et al., 1992; see also Gilbert and Wiesel, 1992).

Although LGN involvement in cortical map reorganization (Eysel et al., 1981; Eysel, 1982) cannot be entirely ruled out, the anatomical organization of the cat LGN may preclude any sizable map reorganization in the visual thalamus. In the LGN it appears that there is a one-to-one connection between retinal ganglion cells and their target LGN units and there is not an extensive network of long horizontal connections (Sherman and Koch, 1986; Kaplan et al., 1987). Previous studies of LGN reorganization after retinal lesions found either no reorganization (Gilbert and Wiesel, 1992) or maximal reactivation effects of the magnitude of only $200 \mu \mathrm{m}$ (Eysel et al., 1981). Thus, the observed functional cortical reactivation can not be accounted for by $L G N$ reorganization.

Identification of the borders of deafferentated cortical areas was facilitated by the fact that the edges of the retinal lesion were very sharp and clean (Figs. 1, 2). Consequently, the lesioned retinal area could be readily and accurately projected onto the tangent screen where the receptive fields were mapped, and by the sequence of receptive field positions in a given penetration we could determine confidently where the normal zone of the retina ended and the lesioned area began. In this respect, it was important to monitor and compensate for eye drifts. Our initial estimates of the borders of the deprived cortex were always in agreement with our post hoc analysis of the response properties of individual neurons; a clear change in contrast threshold almost always coincided with the border between the normal and reorganized zones (Figs. 5, 6).

\section{Normal stimulus selectivity}

How do these initially deafferentated neurons acquire new receptive fields exhibiting relatively normal stimulus selectivity? One possibility is that the observed cortical map reorganization is based on an increase in the synaptic efficacy of existing, but normally subthreshold, connections (e.g., Kaas et al., 1983, 1990; Jenkins et al., 1990; Kaas, 1991, 1994; Chino et al., 1992; Gilbert and Wiesel, 1992; Darian-Smith and Gilbert, 1994; Garraghty et al., 1994). Specifically, within the normal visual cortex, connections to individual neurons extend over much larger areas than those covered by their traditional receptive fields. In normal circumstances these connections are "suppressed" or maintained at subthreshold activity levels (T'so et al., 1986; Hirsch and Gilbert, 1991; Singer, 1993). The sudden bilateral removal of afferent inputs initiates the unnasking of such connections followed by a use-dependent increase in synaptic efficacy during recovery.

At least four currently recognized cortical circuits are capable of influencing responses of a given cortical neuron and thus could potentially be involved in cortical reorganization: feedback connections from extrastriate areas (Bullier et al., 1984; Spear, 1992), the callosal fibers from the contralateral hemisphere (Payne, 1990; Milleret and Buser, 1993), the collateral arbors from neighboring geniculostriate axons outside a cortical cell's traditional receptive field (Freund et al., 1985; Humphrey et al., 1985), and the long-range horizontal connections in the supragranular layers (Gilbert and Wiesel, 1979, 1989; Callaway and Katz, 1991; Katz and Callaway, 1992). Although none of these is mutually exclusive, the present results may provide new insights into which pathways are more likely to be directly involved. Specifically, a direct involvement of feedback connections from extrastriate areas is unlikely because the receptive fields of cells in higher cortical areas which send feedback to striate cortex are extremely large and their retinotopy is far less precise and orderly (Spear, 1992). Furthermore, the range of stimulus selectivity of reactivated neurons in this study is quite different from those of extrastriate units (Spear, 1992). A direct callosal influence also fails to explain the observed orderliness of retinotopy in that very orderly small receptive field progressions of reactivated neurons began at least $5^{\circ}$ away from the vertical meridian into the contralateral peripheral visual field (Figs. 5, 6). If there were significant callosal influences, the receptive fields would have appeared on or near the vertical meridian in the ipsilateral visual field.

The width of a given geniculocortical axon arbor may be as wide as 2-3 mm (Freund et al., 1985; Humphrey et al., 1985) and potentially capable of providing a pathway for laterally spreading signals during "rapid" or "immediate" map reorganization (Chino et al., 1992; Gilbert and Wiesel, 1992). However, unlike the somatosensory system (Garraghty et al., 1994), the involvement of geniculate axon arbors in the map reorganization following extended periods of recovery appears to be minimal for two reasons. First, the cortical distance covered by map reorganization following long recovery periods was found to be much larger (e.g., 6-8 $\mathrm{mm}$ ) than the distance covered by the widths of the largest geniculostriate axon arbors (Kaas et al., 1990; Gilbert and Wiesel, 1992). Second, because the normal orientation tuning and direction selectivity of simple cells are known to depend critically on the precise spatial and temporal convergence of geniculate inputs (Hubel and Wiesel, 1962; Ferster, 1986, 1987, 1988; Reid et al., 1991; Saul and Humphrey, 
1992), it would be expected, contrary to the present results, that stimulus selectivity of reactivated units would be abnormal.

The anatomical substrate most likely to be involved in a largescale map reorganization appears to be the intrinsic long-range horizontal connections in the supragranular layers (Rockland and Lund, 1983; Gilbert and Wiesel, 1989, 1992; Callaway and Kat7, 1991; Darian-Smith and Gilbert, 1994). These axons may extend laterally as far as $8 \mathrm{~mm}$, which corresponds well to the largest cortical distance recovered by map reorganization in area 17 (Kaas et al., 1990; Gilbert and Wiesel, 1992). Moreover, these extended processes are known to exclusively interconnect neurons that exhibit very similar response properties (c.g., T'so et al., 1986; T'so and Gilbert, 1988), indicating that the laterally spreading signals through these connections may already contain information on stimulus selectivity. Furthermore, since these connections form during normal development, even the subthreshold connections would presumably be consistent with mediating normal response properties. 'I'hus, the hypothesis that the intrinsic horizontal connections are involved in cortical map reorganization nicely dovetails with our present findings that stimulus orientation and direction and spatial frequency selectivity of reactivated neurons are remarkably normal provided that high-contrast stimuli are used.

\section{Reduced contrast sensitivity and maximum response amplitude}

Assuming that laterally spreading signals through the long-range intrinsic horizontal connections are responsible for the activation of initially deafferentated neurons, why is the overall responsiveness of these reactivated neurons reduced? Recent studies have demonstrated that the sensitivity of a given neuron in the normal visual cortex is determined not only by its direct afferent inputs, but also by the timely summation of often subthreshold inputs from many sources (Gilbert and Wiesel, 1990; Hirsch and Gilbert, 1991; Katz and Callaway, 1992; Burkhalter et al., 1993; Singer, 1993). Thus, while the initially latent connections are activated and functionally strengthened during recovery periods (presumably by a use-dependent synaptic potentiation of the existing connections), removing all direct afferent inputs to a given neuron in our experimental subjects is likely to have caused a substantial decrease in the overall strengths of excitatory drive to that neuron. The elevated contrast thresholds and reduced maximum response amplitude that we found in reactivated units are consistent with the "long-range horizontal connection hypothesis" described above.

\section{Functional significance}

One of the major conclusions of this study is that reactivated striate cortical neurons are capable of sending functionally meaningful signals to more central structures provided that the visual scene contains moderately high contrast images. It remains to be seen if reactivated neurons influence perception in consistent ways. Growing evidence indicates that although adult humans who develop bilateral lesions commonly exhibit scotomas when tested with static perimetric methods, they often report perceptual "filling-in" of scotomas (e.g., Sergent, 1988). Moreover, the human blind spot is commonly "filled in" (e.g., Kawabata, 1984; Brown and Thurmond, 1993; Tripathy and Levi, 1994) and artificially induced scotoma in one eye was also rcported to be filled in (e.g., Ramachandran and Gregory, 1991). In all cases, stimuli imaged around scotomas could presumably gain higher weight in outcomes based on population coding in that the stimuli would activate both the normal complement of cortical neurons as well as the neurons within the scotomas. Stimuli near a scotoma might now capture visual "attention" more effectively than retinotopically comparable stimuli distant from the scotoma. Obviously, this sort of speculation must be more directly tested before any firm conclusions can be made. It is certain, however, that our present findings on the normal response properties of reactivated neurons make studies of adult cortical plasticity associated with map reorganization more interesting and worthwhile.

\section{References}

Barlow HB, Blakemore C, Pettigrew JD (1967) The neural mechanisms of binocular depth discrimination. I Physiol (I ond) 193:327-342.

Barlow HB, Derrington AM, Harris LR, Lennic P (1977) The effects of remote retinal stimulation on the responses of cat retinal ganglion cells. J Physiol (Lond) 269:177-194.

Brown RJ, Thurmond JB (1993) Preattentive and cognitive effects on perceptual completion at the blind spot. Percept Psychophysiol 53: $200-209$.

Bullier J, Kennedy H, Salinger W (1984) Branching and laminar origin of projections between visual cortical areas in the cat. J Comp Neurol 228:329-341.

Burkhalter AB, Bernardo KL, Charles V (1993) Development of local circuits in human visual cortex. J Neurosci 13:1916-1931.

Callaway EM, Katz LC (1991) Effects of binocular deprivations on the development of clustered horizontal connections in cat striate cortex neurons. Proc Natl Acad Sci USA 88:745-749.

Carroll EW, Wong-Riley MTT (1984) Quantitative light and electron microscopic analysis of cytochrome oxidase-rich zones in the striate cortex of the squirrel monkey. J Comp Neurol 222:1-17.

Chino YM, Shansky MS, Jankowski WL, Banser FA (1983) Effects of rearing kittens with convergent strabismus on the development of receptive field properties in striate cortex neurons. J Neurophysiol 50:265-286.

Chino YM, Smith EL III, Wada H, Ridder WL, Langston AL, Lesher GA (1991) Disruption of binocularly correlated input leads to defects in spatial properties of striate cortical neurons in cats. J Neurophysiol 65:841-859.

Chino YM, Kaas JH, Smith EL, Langston AL, Cheng H (1992) Rapid reorganization of cortical maps in adult cats following restricted deafferentation in retina. Vision Res 32:789-896.

Chino YM, Smith EL, Yoshida K, Cheng H, Hamamoto J (1994) Binocular interactions in striate cortical neurons of cats reared with discordant visual inputs. J Neurosci 14:5050-5067.

Darian-Smith C, Gilbert CD (1994) Axonal sprouting accompanies functional reorganization in adult cat striate cortex. Nature 368:737740.

Eysel UT (1982) Functional reconnections without new axonal growth in a partially denervated visual relay nucleus. Nature 299:442-444.

Eysel UT, Gonzalez-Aguiler F, Mayer U (1981) Reorganization of retino-geniculate connections after retinal lesions in the adult cat. In: Lesion-induced neuronal plasticity in sensorymotor systems (Florhr $\mathrm{H}$, Precht $\mathrm{H}$, eds).

Ferster D (1986) Orientation selectivity of synaptic potentials in neurons of cat primary visual cortex. J Neurosci 6:1284-1301.

Ferster D (1987) Origin of orientation-selective EPSPs in simple cells of cat visual cortex. J Neurosci 7:1780-1791.

Ferster D (1988) Spatially opponent excitation and inhibition in simple cells of the cat visual cortex. J Neurosci 8:1172-1180.

Freund T, Martin KAC, Whitridge D (1985) Innervation of cat visual areas 17 and 18 by physiologically identificd X- and Y-type thalamic afferents. I. Arborization patterns and quantitative distribution of postsynaptic elements. J Comp Neurol 242:263-274.

Friedlander MJ, Tootle JS (1990) Postnatal anatomical and physiological development of the visual system. In: Development of sensory systems in mammals (Coleman JR, ed), pp 61-124.

Garraghty PE, Sur M (1993) Competitive interactions influencing the development of retinal axon arbors in the cat lateral geniculate nucleus. Physiol Rev 73:529-545.

Garraghty PE, Kaas JH, Florence SL (1994) Plasticity of sensory and motor maps in adult and developing mammals. In: Advances in neural and behavioral development (Casagrande VA, Shinkman PG, eds) pp 1-36. Ablex. 
Gilbert CD, Wiesel TN (1979) Morphological and intracortical projections of functionally identified neurons in cat visual cortex. Nature 280:120-125.

Gilbert CD, Wiesel TN (1989) Columnar specificity of intrinsic horizontal and corticocortical connections in cat visual cortex of the cat. J Neurosci 9:2432-2442.

Gilbert CD, Wiesel TN (1990) The influence of contextual stimuli on the orientation selectivity of cells in the primary visual cortex of cats. Vision Res 30:1689-1701.

Gilbert CD, Wiesel TN (1992) Receptive ficld dynamics in adult primary visual cortex. Nature 356:150-152.

Heinen SJ, Skavenski AA (1991) Recovery of visual responses in foveal V1 neurons following bilateral foveal lesions in adult monkey. Exp Brain Res 83:670-674.

Hirsch JA, Gilbert CD (1991) Synaptic physiology of horizontal connections in the cat's visual cortex. J Neurosci 11:1800-1809.

Hubel DH, Wiesel TN (1962) Receptive fields, binocular interactions and functional architecture in the cat's visual cortex. J Physiol (Lond) 160:106-154.

Humphrey AL, Sur AL, Uhlrich DJ, Sherman SM (1985) Projection patterns of individual $X$ - and $Y$-cell axons from the lateral geniculate nucleus to cortical area 17 in the cat. J Comp Neurol 233:159-189.

Jenkins WM, Merzenich MM, Ochs MT, Allard T, Guic-Robles E (1990) Functional reorganization of primary somatosensory cortex in adult owl monkeys after behaviorally controlled tactile stimulation. J Neurophysiol 63:82-104.

Kaas JH (1991) Plasticity of sensory and motor maps in adult mammals. Annu Rev Neurosci 14:137-167.

Kaas JH (1994) The reorganization of sensory and motor maps in adult animals. In: Molecular and cellular plasticity, pp 51-71.

Kaas JH, Merzenich MM, Killackey HP (1983) The reorganization of somatosensory cortex following peripheral nerve damage in adult and developing mammals. Annu Rev Neurosci 6:325-356.

Kaas JH, Krubitzer LA, Chino YM, Langston AL, Polley EH, Blair N (1990) Reorganization of retinotopic cortical maps in adult mammals after lesion of the retina. Science 248:229-231.

Kaplan E, Purpra K, Shapley RM (1987) Contrast affects the transmission of visual information through the mammalian lateral geniculate nucleus. J Physiol (Lond) 391:267-288

Katz LC, Callaway EM (1992) Development of local circuits in mammalian visual cortex. Annu Rev Neurosci 15:31-56.

Kawabata N (1984) Perception at the blind spot and similarity grouping. Percpept Psychophysiol 36:151-158.

McIlwain JT (1966) Some evidence concerning the physiological basis of the periphery effects in the cat's retina. Exp Brain Res 1:265-271.

Milleret C, Buser P (1993) Reorganization processes in the visual cortex also depend on visual experience in the adult cat. In: Progress in brain res, Vol 95 (Hicks TP, Molotchnikoff S, Ono T, eds), pp 257 269. Amsterdam: Elsevier.

Mitchell DE, Timney B (1984) Postnatal development of function in the mammalian visual system In: Handbook of physiology, Vol 3, Sec 1, Nervous system, III (Darian-Smith I, ed), pp 507 555. Washington, DC: American Physiological Society.

Movshon JA, Kiorpes L (1990) The role of experience in visual development. In: Development of sensory systems in mammals (Coleman JR, ed), pp 156-202. New York: Wiley.

Movshon JA, Kiorpes L (1993) In: Early visual development, normal and abnormal (Simons K, ed), pp 296-305. New York: Oxford UP.
Movshon JA, Van Sluyters RC (1981) Visual neural development. Annu Rev Psychol 32:477-522.

Movshon JA, Tolhurst DJ, Thompson ID (1978) Spatial and temporal contrast sensitivity of neurons in areas 17 and 18 of the cat's visual cortex. J Physiol (Lond) 283:101-120.

Payne B (1990) Representation of the ipsilateral visual field in the transition zone between areas 17 and 18 of the cat's cerebral cortex. Vis Neurosci 4:445-474.

Pettigrew JD, Cooper ML, Blasdel GG (1979) Improved use of tapetal reflection for eye-position monitoring. Invest Ophthalmol Vis Sci 18: 490-495.

Ramachandran VS, Gregory RL (1991) Perceptual filling-in of artificially induced scotomas in human vision. Nature 350:699-702.

Rauschecker JP (1991) Mechanisms of visual plasticity: Hebb synapses, NMDA receptors, and beyond. Physiol Rev 71:587-615.

Reid C, Soodak RE, Shapley RM (1991) Directional selectivity and spatiotemporal structure of receptive fields of simple cells in the cat's striate cortex. J Neurophysiol 66:505-529.

Rockland KS, Lund JS (1983) Intrinsic laminar lattice connections in primate visual cortex. J Comp Neurol 216:303-318.

Sasaki Y, Chino YM, Smith EL III, Kaas JH, Cheng H, Yoshida K (1994) Response properties of newly activated neurons in the reorganized cortex of adult cats following a retinal lesion. Invest Ophthal Vis Sci [Suppl] 35:1774.

Saul AB, Humphrey AL (1992) Evidence of input from lagged cells in the lateral geniculate nucleus of simple cells in cortical area 17 of the cat. J Neurophysiol 68:1190-1208.

Schmid LM, Calford MB, Rosa MGP (1993) Reorganizational plasticity in the primary visual vortex (V1) of adult cats occurs following monocular retinal lesions. Soc Neurosci Abstr 19:1801.

Schmid LM, Calford MB, Rosa MGP (1994) Reorganization in the primary visual cortex (V1) of adult cats occurs immediately following monocular retinal lesions. Invest Ophthal Vis Sci [Suppl] 35: 1774.

Sergent J (1988) An investigation into perceptual completion in blind areas of the visual field. Brain 111:347-373.

Sherman SM, Koch C (1986) The control of retinogeniculate transmission in the mammalian lateral geniculate nucleus. Exp Brain Res 63:1-20.

Sherman SM, Spear PD (1982) Organization of visual pathways in normal and visually deprived cats. Physiol Rev 62:738-855.

Singer W (1993) Synchronization of cortical activity and its putative role in information processing and learning. Annu Rev Physiol 55: 349-374.

Skottun BC, DeValois RL, Grosh DH, Movshon JA, Albrecht DG, Bonds AB (1991) Minireview: classifying simple and complex cells on the basis of response modulation. Vision Res 31:1079-1086.

Spear PD (1992) Functions of extrastriate visual cortex in non-primate species: In: Vision and visual dysfunction, Vol 4 (Leventhal AG, ed), pp 339-370. Boca Raton, FL: CRC.

T'so DY, Gilbert CD (1988) The organization of chromatic and spatial interactions in the primate striate cortex. J Ncurosci 8:1712-1727.

T'so DY, Gilbert CD, Wiesel TN (1986) Relationships between horizontal connections and functional architecture in cat striate cortex as revealed by cross-correlation analysis. J Neurosci 6:1160-1170.

Tripathy SP, Levi M (1994) Long-range dichoptic interactions in the human visual cortex in the region corresponding to the blind spot. Vision Res 34:1127-1138. 